Fall 12-1-2020

\title{
An Altitude Adjustment: Implementing a Clinical Practice Guideline in the Newborn Nursery at Moderate Altitude
}

Leeann Blaskowsky

I.blaskowsky@usa.edu

DOI: https://doi.org/10.46409/sr.ITR03352

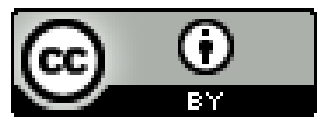

This work is licensed under a Creative Commons Attribution 4.0 License.

Follow this and additional works at: https://soar.usa.edu/scholprojects

Part of the Maternal, Child Health and Neonatal Nursing Commons, and the Pediatric Nursing Commons

\section{Recommended Citation}

Blaskowsky, L. (2020). An Altitude Adjustment: Implementing a Clinical Practice Guideline in the Newborn Nursery at Moderate Altitude. [Doctoral project, University of St Augustine for Health Sciences]. SOAR @ USA: Student Scholarly Projects Collection. https://doi.org/10.46409/sr.ITR03352

This Scholarly Project is brought to you for free and open access by the Student Research at SOAR @ USA. It has been accepted for inclusion in Student Scholarly Projects by an authorized administrator of SOAR @ USA. For more information, please contact soar@usa.edu, erobinson@usa.edu. 
An Altitude Adjustment: Implementing a Clinical Practice Guideline for Oxygen in the Newborn Nursery at Moderate Altitude

Leeann M. Blaskowsky, MSN, NNP-BC, C-ELBW School of Nursing, University of St. Augustine for Health Sciences

This Manuscript Partially Fulfills the Requirements for the

Doctor of Nursing Practice Program and is Approved by:

Sarah M. I. Cartwright, DNP, MSN-PH, BAM, RN-BC, CAPA, FASPAN

Kathleen Flarity, DNP, PhD, CEN, CFRN, FAEN

December 1, 2020 
University of St. Augustine for Health Sciences

DNP Scholarly Project

Signature Form

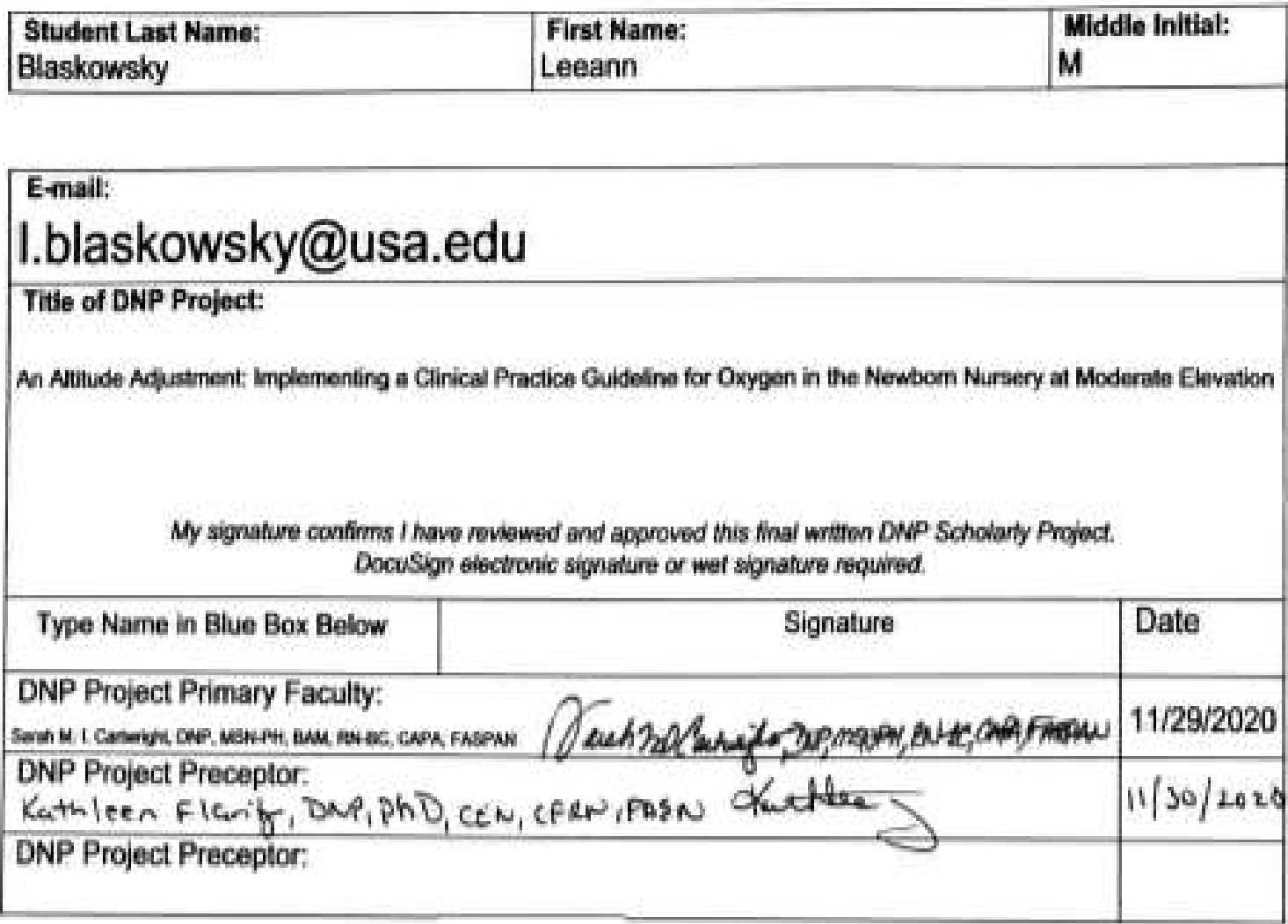




\begin{abstract}
Practice Problem: All infants undergo many changes at birth, but for some, the transition from intrauterine to extrauterine life presents more of a challenge, especially at altitude. Despite continuing research, neonatal prescribing guidelines for oxygen therapy remain ambiguous. PICOT: For term and late preterm infants requiring oxygen beyond transition, does a clinical practice guideline compared to practice without a guideline, provide consistent, evidence-based care, support the mother-infant dyad, and impact nursing perceptions over a six-week pilot period?
\end{abstract}

Evidence: Birth at moderate altitude presents the newly born with less oxygen than those delivered at sea level. Several studies have assessed the differences and make recommendations for modifying acceptable saturations or compensating with a small amount of nasal cannula oxygen (the "altitude adjustment"), but recommend further study before broad application. Intervention: A consensus guideline for oxygen administration, weaning, and echocardiogram for indeterminate CCHD screens was created and implemented to facilitate care and practice consistency for patient safety and maintain the mother/infant dyad in a unique nursery setting.

Outcome: After implementation, two infants demonstrated persistent pulmonary hypertension of the newborn, were treated with supplemental oxygen, and had normal ECHOs for age at discharge. These babies may have worsened without supportive treatment or required rehospitalization, demonstrating clinical significance for the pathway in the guideline. Conclusion: A shared-practice guideline for infants requiring supplemental oxygen following delivery was the focus of this EBP project. Evidence supports practice consistency by using guidelines and pathways across many disciplines, and engaging nurses in bringing evidencebased practice to the bedside improves patient outcomes. 


\section{An Altitude Adjustment: Implementing a Practice Guideline for Oxygen Administration in the Newborn Nursery at Moderate Elevation}

Recent changes in the pediatric care landscape in Colorado Springs have nurses and providers caring for term ( $\geq 37$ weeks gestation) and late preterm ( $\geq 35-37$ weeks gestation) infants in the normal newborn nursery asking questions, particularly around the topic of oxygen administration following delivery and beyond transition. At birth, all infants undergo many complex physiological changes involving the pulmonary and cardiovascular systems, and most do so with relative ease (Hooper et al., 2019). For some, the transition from life inside the uterus to outside presents more of a challenge. For these infants, increased monitoring of vital signs and supplemental oxygen administration potential is not uncommon, especially at altitude (Paranka et al., 2017).

The landmark reports from the Institute of Medicine, To Err is Human (1999) and Crossing the Quality Chasm (2001) brought attention to the importance of patient safety and quality of care. The inefficiencies of translating evidence into healthcare practice persist, even decades later. The need to provide best-practice care brought sweeping changes to many organizations, shifting from legal and regulatory compliance to bringing evidence to the bedside (Dols et al., 2017). This shift in practice also created the need for transformational leadership and innovation (White et al., 2016).

In the acute care setting, questioning current practice and searching the literature for evidence thrives. This project, incorporating these elements, created and implemented a clinical practice guideline (CPG) for oxygen administration in a newborn nursery at 6,200 ft. elevation, moderate altitude (Department of the Army, 2002). Several novel features impact the care of term and late preterm infants at this location. The project detailed the significance of the practice 
problem, posed a practice question in PICOT format, and described the creation of a guideline with practice recommendations to impact the consistency of care and nursing stressors related to recent organizational changes. As an evidence-based practice (EBP) project, the data collection points evaluated the CPG's effectiveness, monitored patient safety during the implementation, and included a plan for sustainability.

\section{Significance of the Practice Problem}

Oxygen is essential for life. Once considered harmless and given freely to all, oxygen has also been critically examined for its potential to produce at least as much harm as benefit (Perrone et al., 2017). The potential for harm was first identified in 1954 with a National Institutes of Health (NIH) study linking blindness to the excessive amounts of oxygen given to premature infants in incubators (as cited in National Eye Institute, n.d.). More recent research revealed the development of reactive oxygen species (ROS) associated with oxidative stress causing lung and retinal damage or lead to other types of inflammatory injury (Perrone et al., 2017). These historic discoveries demonstrate the core principles for evidence-based practice: using data-driven research to provide the safest care for patients (Melnyk \& Fineout-Overholt, 2015). Despite continuing research, prescribing parameters for neonatal oxygen therapy remain ambiguous with persistent provider concerns for patient safety and quality of care.

The city of Colorado Springs, nestled at the foot of Pikes Peak, is home to just over 700,000 people (Colorado Springs Chamber \& EDC, 2020). At approximately 6,200 feet elevation, the nurseries at one community-based institution are divided over two campuses, labeled as "Central" and "North," owing to their geographic placement within the city. Although within the same hospital system, care was different at each of the nurseries. Historically, the Central campus staff followed a "C acuity" order set derived from neonatal intensive care unit 
(NICU) admission services that permitted oxygen in the normal newborn nursery but lacked practice protocols for care. Physical space limitations at the North campus prevented any extended observation or additional care. The nurses did not use the $\mathrm{C}$ acuity order set and were not trained or expected to care for these patients. Infants requiring oxygen were sent to the small, six-bed level II NICU located on the labor and delivery floor.

Historically, the Central campus provided most of the labor and delivery/newborn care within the city. The construction of a free-standing children's hospital on the North campus grounds relocated and expanded pediatric care and moved most neonatal intensive care to that building. This change also geographically shifted many obstetrical care providers and services. The relocation prompted system administrators to enlarge the existing facility at North by building a bridge-like wing to house the expanded obstetrical and newborn care services. A substantial shift in patient volumes began with the opening of the expansion in March of 2019.

Staffing projections for the realignment underestimated patient volumes with vast numbers of displaced or new staff orienting and training to modified or completely new roles. Separate staff and management for each of the nurseries, with an aspiration for unification, meant restructuring the entire service line. Bedside nurses also reported dramatically increased stress levels. Additionally, given concerns for validity and patient safety, the $\mathrm{C}$ acuity order set was removed from practice leaving providers with little guidance for consistency in care. Each of these changes pointed to multiple gaps in care.

In practice, the other normal newborn (Level I) nurseries within this 12-hospital regional system transferred all newborns requiring supplemental oxygen to their NICUs. The NICU on the North campus, however, is now located within the free-standing children's hospital. An infant, transferring for a higher level of care, passed through a logistical, one-way door without 
the ability to return to the mother's room if the infant's condition improved. Even if the need for oxygen was resolved, the mother/infant dyad remained separated throughout the hospital stay. Emerging evidence indicated that this extended separation might cause harm (Császár-Nagy \& Bókkon, 2018). The one-way transfer created a unique practice setting for care in this nursery and was identified as another gap in care.

The 2012 American Academy of Pediatrics (AAP) Policy Statement addressed levels of neonatal care. The AAP supports standardized nomenclature to promote consistency, reflecting the overall evidence for neonatal care. A Level I classification provides a basic level of care for low-risk newborns at term ( $>37$ weeks gestation) and late preterm ( $\geq 35-37$ weeks gestation) infants, who are "physiologically stable" (AAP, 2012, p. 592). The statement, however, offers no distinct definition of physiologic stability. The next classification, Level II, includes infants $\geq 32$ weeks gestation and $\geq 1500$ grams at birth and those requiring positive pressure respiratory support or mechanical ventilation up to 24 hours. These parameters create a fairly sizable "gray area" population that this project sought to address.

Practicing at altitude presented another challenge. Many studies, across the literature, supported lower oxygen saturations at altitude (Gonzalez-Andrade et al., 2018; Parakna et al., 2017; Tekleab \& Sewnet, 2019). Providers have historically presumed and related that approximately $10 \%$ of the term and late preterm infants born at this altitude require a small amount of oxygen (traditionally accepted as $\leq 60 \mathrm{~mL}$ via nasal cannula) beyond transition. This oxygen need is referred to as the "altitude adjustment" in practice and supported in the literature (Parakna et al., 2017). At this location, most providers also allowed infants to return to their mother's room if they remained stable on that small amount of oxygen for some time. No concrete parameters for defining "small" and "some" existed. 
Further, the critical congenital heart disease (CCHD) screen, recommended to become part of routine screening panels for discharge from the nursery in 2011, was implemented in all 50 states by 2018 (Grazel, 2018). The Centers for Disease Control and Prevention (CDC) reported that congenital heart defects affected approximately 1\% of all births (CDC, 2018). About $25 \%$ of those infants had a critical defect, which required immediate intervention. Grazel (2018) reported a 33\% decline in infant deaths, directly attributable to CCHD screening, in the first eight states that mandated the screen in 2013.

As a part of routine newborn testing, infants $\geq 24$ hours of age have pulse oximetry measurements pre-ductal (right arm) and post-ductal (any other extremity), referring to the anatomical placement of the ductus arteriosus within the fetal/neonatal heart (Hooper et al., 2019). Infants who cannot maintain a saturation of $>90 \%$ in room air or with a difference of $>3 \%$ between the readings fail the screen. If the infant fails the screen, then an echocardiogram is recommended to assess for the presence of critical congenital heart disease.

Some pediatric hospitalist providers considered the need for any oxygen, an indeterminate screen, an automatic fail prompting an echocardiogram. In contrast, others ignored the small amount of oxygen as "correcting for altitude" without obtaining an echocardiogram, which created an inconsistent practice for patient care. In 2017, Paranka et al. reported that false negatives increased from $0.1 \%$ to $6 \%$ with the latter practice. An informal discussion with the children's hospital pediatric cardiology service medical director revealed their group's preference for a screening echocardiogram for any oxygen requirement at 24 hours of age, as recommended in the supporting literature. Since patient safety is essential, further investigation for practice recommendations was warranted, and another gap in care was identified. 
An additional indication for oxygen extending beyond the transitional period is persistent pulmonary hypertension of the newborn, known as PPHN (Lakshminrusimha et al., 2016). Ongoing research continues to increase understanding of the physiologic impact and management for this diagnosis (Lakshminrusimha et al., 2016). Formerly known as persistent fetal circulation, this condition prolongs the hypoxic pulmonary vasoconstriction of the intrauterine environment after delivery. While remaining within the uterine environment, the placenta is responsible for the elemental gas exchanges essential for fetal life. The blood is principally shunted from the lungs via the ductus arteriosus, allowing only enough for alveolar (lung) growth. When the infant delivers and the umbilical cord is clamped, the lungs take over the gas exchange, and pulmonary vascular resistance (PVR) must decrease to facilitate blood flow to the lungs. If the PVR remains higher than the systemic blood pressure, a state of hypoxia persists with the potential for tissue injury and respiratory failure (Lakshminrushimha et al., 2016). This condition can occur on a spectrum of severity: mild hypoxia with elevated pulmonary artery pressures on echocardiogram, through the most severe, hypoxic respiratory failure requiring intensive management and significant support. Assessing severity and the potential for decompensation, which can be rapid and catastrophic, suggested a need for practice recommendations to support patient safety. As a planned part of the CPG creation, this condition was also included in the discussion with the cardiology director.

Finally, nursing staff expressed concerns for patient safety, recognized the inconsistencies in care, and self-reported increases in work stress related to these practice issues. The pediatric hospitalist group also identified concerns for patient safety and care. The hospitalists elected to address the gaps in care by developing a guideline for care with practice recommendations, which Olswang and Goldstein noted to be beneficial (2017). With an easy 
reference algorithm, the CPG guided nursing staff and offered consensus practice recommendations for using oxygen in the nursery and addressed the final gap in care.

\section{PICOT Question}

Asking a question is the foundation for evidence-based practice (EBP), and using a common language facilitates understanding for others. Expressing the practice problem in a PICOT format addressing population, intervention, comparison, outcome, and time promotes this standardization (Melnyk \& Fineout-Overholt, 2015). The PICOT question for this change project was: For term and late preterm infants requiring oxygen beyond transition, does a clinical practice guideline (CPG) with nursing education and provider practice advice compared to traditional practice without a guideline, provide evidence-based care, support the mother-infant dyad, and impact nursing perceptions related to practice consistency over a six-week pilot period?

Term and late preterm infants admitted to the newborn nursery at both the Central and North campuses following delivery served as the intervention's target population. All infants that required oxygen following delivery and beyond transition were candidates for the change implementation. Infants who required more than $250 \mathrm{~mL}(0.25 \mathrm{~L} / \mathrm{min})$ of oxygen via low flow nasal cannula (LFNC), positive pressure of any kind, or transferred to the neonatal intensive care unit (NICU) following delivery were excluded. The nurses who cared for these patients also gave input on occupational stress and engagement perceptions. Nursing questions were extracted from an existing, validated tool first described by Gray-Toft and Anderson in 1981.

Implementing an evidence-based CPG for using oxygen in the normal newborn nurseries at moderate altitude was the intervention. The project developed components for oxygen initiation, weaning parameters, CCHD screening on oxygen with echocardiogram 
recommendations, and maintaining the mother/infant dyad whenever possible. The $\mathrm{CPG}$ produced the desired outcomes of consistency for infant care without a missed diagnosis and reduced nursing stress. Following education, patients who received oxygen utilizing the CPG for four weeks were compared to patients who received oxygen using the current practice without a guideline for a randomly selected two-month period before the CPG implementation.

\section{EBP Framework and Change Theory}

In 1951, Kurt Lewin proposed a theory that remains a classic overarching philosophy for organizational change. His three-phase model (unfreezing, changing, and refreezing) focuses on the forces driving change rather than on the change itself and lends itself well to quality improvement and evidence-based practice modifications (Lewin, 1951). The first phase allows innovative thought to change the current status by altering the oppositional forces keeping things the same. This transformation is accomplished by either increasing propelling forces or removing resistance. The next phase makes the change and assesses for a balance of the oppositional forces to demonstrate improvement. The final phase focuses on sustainability.

At the core of change is transformational leadership, when leaders inspire others to achieve and optimize performance. The 12-hospital system where this Doctor of Nursing Practice (DNP) evidence-based practice (EBP) project took place demonstrated this leadership with an existing evidence-based practice framework. The Iowa Model Revised: Evidence-Based Practice to Promote Excellence in Health Care (Iowa Collaborative Model, 2017; Titler et al., 2001) was vetted and actively used at the organization. As a theoretical-process model, it guides individuals to thinking critically about current practice and determine ways to improve care activities. The process has five phases: assess practice, decide, plan, intervene, and evaluate. 
As previously noted, the assessment of practice propels the formulation of a clinical question as the basis for EBP. Delivering oxygen in the normal newborn nursery could be done better; providers knew it, management knew it, and nurses knew it. An assessment of existing practice generated questions about a patient care issue creating the problem-focused trigger identified as the initial step, "assess practice," in the Iowa Model (Iowa Collaborative Model, 2017). The Central and North nurseries were caring for the same patients as other nurseries in the system, but several distinct factors impacted this unique practice environment.

The second phase, "decide," was used to address institutional priorities, such as the organization's patient safety goals for quality care using the best available evidence (Iowa Collaborative Model, 2017). The unit management, concerned about meeting these goals, asked for the CPG, and emphasized administrative concerns for patient safety and satisfaction as drivers for reimbursement and community share (UCHealth, 2020). During this phase, a team was assembled as suggested (Iowa Collaborative Model, 2017). This model also addressed several DNP essentials by applying quality improvement methods, utilizing informatics, employing EBP, and working in interdisciplinary teams (American Association of Colleges of Nursing, 2020).

Identifying internal and external resources was essential for implementing practice change. One of those resources was the literature search, along with critical appraisal and evaluation. Involving the stakeholders in the proposed modification and the processes involved facilitates making the change and ensures sustainability (White et al., 2016). Critically appraising and synthesizing the literature assisted in developing the project plan.

The third phase, "plan," incorporated writing the CPG, determined data management, and detailed the implementation methods. The fourth phase, "intervene," implements the practice 
change. This phase began with the education and training required for the project and established practice champions: those available as a resource for practice questions once the change started (White et al., 2016). Finally, the fifth phase, "evaluate," analyzes the process outcomes and identifies any practice change modifications.

\section{Evidence Search Strategy}

A search for current, peer-reviewed articles was conducted in multiple databases via the University of St. Augustine for Health Sciences (USAHS) online library. These databases included Gale Academic One File, Directory of Open Access Journals, CINAHL, and Academic Search Index. A separate search of PubMed was also conducted. A search in Google Scholar identified any additional open access articles.

The following search terms were utilized to locate articles: "newborn" and "oxygen" with variations of the terms, including "neonatal," "term," and "late preterm." The addition of "altitude" narrowed the results. The databases also added MeSH terms that included "infant/neonatal" and "oxygenation" for the search. The search was further narrowed with the addition of two filters: date range from 2015-2020 and peer-reviewed. Adding the Boolean modifiers "AND" between the keywords and "NOT" with additional exclusionary terms "premature" and "ventilation" further decreased the articles.

Most of the evidence for CCHD screening was amassed before the AAP recommendations for universal screening became a practice standard in 2011 and was omitted from the review. An additional search for CCHD screening with the previously noted date and peer-reviewed limiters was added to assess any current data for the screen. A single Cochrane review related to CCHD screening provided a summative review and was retained for use. An additional search for "maternal separation" and "harm" on Google Scholar provided more 
background information on this nursery's unique circumstances. A further search for existing oxygen in the newborn nursery guidelines and practice standards via UpToDate, the AAP, and the National Association of Neonatal Nurses (NANN) websites revealed none in current use.

\section{Evidence Search Results and Evaluation}

The initial literature search of the USAHS library with broad terms generated more than 350,000 results. Several modifications of the broad terms "newborn" and "oxygen" to include "neonatal" and "administration" did little to reduce that number. The addition of "altitude" decreased the returns significantly but not enough to achieve a manageable list. The addition of date "2015-2020" and "peer-reviewed" limiters further narrowed the results. There were, however, still more than 60,000 results. The addition of Boolean terms using "newborn NOT premature AND oxygen NOT ventilator AND altitude" with date limiters 2015-2020 yielded 278 returns. A separate search for "PPHN NOT sildenafil NOT ventilation" yielded an additional 285 results. Adding similar date and peer-reviewed limiters to this search decreased the returns. Both searches were combined to reach the 405 total articles noted in Figure 1.

The adjusted CCHD search produced several studies of the screening but no true experimental models. These articles did, however, offer supportive scientific data for the continued use of CCHD screening. The abstracts of the articles were reviewed before a full-text appraisal. A review of the full-text produced several articles with repetitive or noncontributory information. Those articles were eliminated from the evaluation. Several non-research articles providing background information were also excluded from the evidence evaluation. A generalized guide for oxygen use, published by the World Health Organization (WHO), was reviewed and reserved for background information (WHO, 2016). 
One of the standards for bringing evidence to the bedside utilizes scientific evidence found in the available literature to inspire, support, or disprove innovative thoughts regarding leadership, education, or practice (Moran et al., 2020). However, it is not enough to read the research and presume that peer-reviewed publication documents the information validity of the information presented. Critical appraisal of the evidence is an essential element for assessing the information presented. The Johns Hopkins Nursing Evidence-Based Practice (JHNEBP) model provides a validated tool for assessing the evidence (Dang \& Dearholt, 2018). The JHNEBP model provides both a rating hierarchy, "Level," and quality rating, "Grade," for research evidence with broad terms to help the novice investigator assess the strength of the evidence (Dang \& Dearholt, 2018). While providing a directed structure, this tool also allows for clinical judgment and critical thinking to derive conclusions about the evidence. By assigning both a level of evidence and quality within that level, the reader critically appraises the strength of the information, such as opinion versus an experimental model with comparative intervention groups. Once the search was refined, a more manageable pool of information emerged and is presented in Appendices A and B with the JHNEBP rating criteria. Although not achieving the level of a randomized control trial, the studies presented do provide good quality evidence given their relative sample sizes as noted in the evidence tables.

\section{Themes}

The discovery of knowledge is of no use if it is not translated into practice (Moran et al., 2020). For an evidence-based practice project, the literature should be supportive of the practice change. Initially, the literature for this topic appeared overwhelming, given the vast number of results from the initial search. This pool of evidence addressed the use of oxygen in the newborn 
and, separately, the creation of CCHD screening. The evidence also supported the impact of altitude on caring for newborns and tissue oxygenation demands during transition.

Moreover, specific applications regarding the impact of altitude and the unique circumstances for maternal/infant separation have not been as well-studied. Many of the articles also pointed to the need for further research, which extended beyond the limits of this EBP project. These points account for the nonexperimental evidence noted in the evidence table (see Appendix A). As noted by several authors, the data continues to emerge.

The administration of oxygen in the newborn period immediately following delivery has been well-studied (Dilli et al., 2019; Grazel, 2018; Oster et al., 2016; Tekleab et al., 2019) and resulted in the current AAP recommendations for using room air during resuscitation for all term and late preterm infants with recommendations for increasing oxygen only in the setting of a need for positive pressure and for premature infants $\leq 35$ weeks gestation (Kayton et al., 2018; Perrone et al., 2017). Although these recommendations have been broadly applied, several areas are lacking in both evidence and advice. Practice at moderate altitude, specifically 6,200 feet elevation, presents the newly born with less available oxygen than those delivered at sea level. Several studies have assessed the differences and made recommendations for either adjusting the acceptable target saturations or providing a small amount of nasal cannula oxygen to compensate, referred to as the "altitude adjustment" (Guo et al., 2020; Lueth et al., 2016; Paranka et al., 2018).

What is not clear from the evidence is which practice is better since there are no directly comparative studies. While some studies recommend adjusting oxygen saturation tolerances, they each noted more study was needed before it could be generalized. There is also no clear evidence recommending specific, acceptable amounts of oxygen based on a particular altitude. 
However, two of the articles did agree that up to $50 \mathrm{~mL}$ of LFNC oxygen is equal to room air at sea level (Hoffman et al., 2016; Lueth et al., 2016). Scientific calculations from the cardiology practice associated with the organization where the project occurred also supported this theory.

For infants born at sea level, oxygen administration in the newborn period typically indicates the need for more observation and a higher level of care (Perrone et al., 2017). The AAP statement addressing Level I nursery care leaves a large gray area to interpret the "physiologically stable" nomenclature (AAP, 2012). With altitude as a qualifier, does oxygen administration, less than or equivalent to sea-level, make the infant unstable? If the infant is not demonstrating any other signs of difficulty, such as respiratory distress or an inability to feed, should they be considered stable?

The physical constraints created with the construction of the current nursery added another layer of concern. If an infant is deemed unstable and transferred to NICU, the infant cannot return to the mother's room. The transfer separates mother and infant during the entire hospitalization, even if the infant no longer requires supplemental oxygen before discharge. Although there were many others, one citation noted in the evidence addressed the potential for neurodevelopmental harm created with maternal/infant separation (Császár-Nagy \& Bókkon, 2018).

The evidence for CCHD screening as an acceptable, highly specific, and moderately sensitive tool to evaluate newborns for the presence of critical congenital heart disease was wellestablished, as evidenced by the Cochrane review and meta-analysis noted on the table in Appendix B. Further support of CCHD screening was provided by the application to practice in 2011 by the AAP (2012) and CDC (2018). What was less clear, however, was the impact of altitude on routine CCHD screening. Some studies reported no differences (Dilli et al., 2019; 
Tekleab et al., 2019). Others described demonstrable differences and provided recommendations for modifications (Hoffman, 2016; Paranka et al., 2018). The variability in the evidence leads to variability in practice and concerns for patient safety and quality of care. Creating a guideline with practice recommendations was intended to reduce variability and to add to the pool of existing evidence for others to apply in practice.

Further evidence produced in the search relates to PPHN, another condition unique to the transitioning newborn (Lakshminrusimha et al., 2016). PPHN relies heavily on the amounts of oxygen necessary for lowering pulmonary pressures through vasodilation during the shift from intrauterine to extrauterine life. With the impact of altitude and a lower oxygen environment delaying transition, infants can present with an illness severity spectrum from mild to critical. While oxygen administration remains the gold standard for treating PPHN, elevating care needs with increasing symptom severity is also noted in the literature, and recognizing those needs is essential for favorable infant outcomes (Lakshminrusimha et al., 2016).

\section{Practice Recommendations}

Despite recommendations from the Institute of Medicine more than two decades ago, the gaps between research and practice continue. Olswang and Goldstein (2017) discussed the need for many disciplines, including medicine and nursing, to do better. Clinicians should bring evidence to the patients to improve care and outcomes, collaborating with relevant stakeholders, as implementation science evolves. A guideline for practice and patient management provides structure for care and decision-making in real-world applications by implementing the guideline as a pilot for practice (Olswang \& Goldstein, 2017).

The evidence for general oxygen use in the newborn period has evolved in recent years with large volumes of published data relating to practice changes for resuscitation following 
delivery, care for the premature infant, and adoption of universal CCHD screening. What has not been as well studied are two issues addressed by this project: altitude and organizational geography. Creating a CPG was proposed to direct care, facilitate practice consistency, impact outcomes for optimal patient safety, and maintain the mother/infant dyad.

The pilot CPG (see Appendix C) discussed risk factors commonly associated with an oxygen need following delivery. The CPG then detailed specifics for initiating oxygen, continuous monitoring, and notifying the MD/NP for escalating needs as a shared-practice model. Two areas unique to this project are the CCHD screening with echocardiogram (ECHO) parameters and the ability for an infant on LFNC to remain at the mother's bedside during the inpatient hospital stay after monitoring for safety. An algorithm for easy reference was also created (see Appendix D).

Existing practice variability created a way to compare infants to determine if any congenital heart disease (CHD) was detected or missed with practice differences. Some providers ordered an echocardiogram if an infant was on any oxygen at 24 hours as an indeterminate CCHD. Other providers did not order an echocardiogram if an infant was on $\leq 60$ mL LFNC (an "altitude adjustment") and could pass the CCHD screen on that oxygen flow. Infants requiring LFNC oxygen beyond transition would be monitored during a feeding, a deep sleep, plus two additional hours as an extra measure of safety determined by group consensus. Oxygen saturation checks would be obtained during routine vitals, and the infant permitted to "room in" with the mother until discharge. If an infant had PPHN, then oxygen administration, monitoring, and repeat echocardiogram timing, determined with pediatric cardiology recommendations, followed in that section of the CPG. Any persistent issues or care concerns would be monitored and assessed for rapid cycle improvements as detailed in the "Project Plan" 
section. The CPG details practice recommendations with data collection for patient safety that extended beyond this project's time limits and will be evaluated using rapid cycle adjustments after implementation (IHI, 2020). Nursing staff and providers were also given a pathway for reporting concerns to be determined with unit management and the Neonatal Safety and Quality Committee (NSQ).

\section{Project Setting, Stakeholders, and Systems Change}

The setting for this evidence-based practice project was the Level I well newborn nursery in a growing community hospital divided over two campuses at approximately 6,200 feet elevation. Until March of 2019, when a 160,000-square foot addition housing expanded labor and delivery services on the North campus completed and opened, most deliveries occurred at the Central location. The construction of a free-standing children's hospital, changing obstetrical provider locations, and additional facility construction necessitated a geographical switch, with the majority of deliveries changing to the North location.

With a combined annual delivery rate of approximately 4,500 babies, the nurseries had differing approaches to caring for the well newborn and utilizing a structured nursery space. Over the past decade, newborn care trends for "rooming in" recommended moving away from a dedicated nursery space for normal newborn care (Jaafar et al., 2016). North, the newer of the two nurseries built and opened in 2008, had little dedicated nursery space and minimal training for any care not performed at the mother's bedside. The opening of the expanded space without an adjoining NICU created a gap in care recognized by the nursing staff, unit management, hospital administration, and the community providers caring for these newborns (Appendix E). This project is the culmination of discussions on how best to address the gap, creating a CPG for care and training for bedside nurses represented as a mind map (see Figure 2). The stakeholders 
mentioned on the mind map included bedside nurses, nursing management, nurse educators, pediatric hospitalists, pediatric cardiology providers, neonatology providers, respiratory therapists, and, of course, our patients. Also not explicitly mentioned on the mind map are hospital administration and leadership and the DNP student serving as the project manager.

The target organization is part of a network of nationally recognized hospitals and clinics throughout Colorado, southern Wyoming, and western Nebraska (UCHealth, 2020). Through innovation and discovery, the organization seeks to improve the lives of those in the community as a mission with a vision of moving from health care to health. The organization espouses three values: patients first, integrity, and excellence. The Iowa Model Revised: Evidence-Based Practice to Promote Excellence in Health Care $^{\circledR}$ (Iowa Model) is utilized to guide process improvements for clinical and systems issues. As a widely-used process for promoting EBP, the Iowa model's presence validated the organizational culture and support for implementation science and point of care clinician inquiry to drive evidence translation into practice.

\section{Project Overview}

With the organizational mission, vision, and values in mind, this project was created to bring evidence-based practice to the bedside for newborn care. The project mission was to develop a CPG for oxygen use in the newborn nursery. The project's vision had several objectives. First was providing optimal, evidence-based care for term and late preterm infants in the newborn nursery. Next, the impact of altitude on neonatal transition from intrauterine to extrauterine life and supporting this transition while safely minimizing mother and infant separation was addressed. Finally, focusing on nursing concerns for practice variability, a shared practice model guideline engaging both nurses and providers in the care of the newborn was created. 


\section{Project Plan (Method)}

The CPG created for this project addressed the need for an echocardiogram for infants on oxygen at the time of CCHD screening to ensure patient safety supported by the evidence. During the CPG development, infants requiring oxygen at 24 hours of age followed one of two pathways: a reflex ECHO for an indeterminate screen or no ECHO if the infant could pass the CCHD screen on LFNC within defined parameters. The CPG's final version had only one pathway for CCHD screening determined after the preliminary, retrospective data collection illuminated comparative practice determinations. Surprisingly, altering their practice before developing the CPG, many providers were already including an ECHO for an indeterminate CCHD screen. The exception was the neonatology group who objected to the first pathway and raised concerns for increased, perhaps unnecessary, tests. Infants in the PrIP group requiring oxygen were cross-referenced with pediatric cardiology for any potential missed CHD diagnosis. A limitation for this population was that the patients cared for outside the organization's cardiology group could not be assessed or included for comparison.

The neonatology group raised concerns for an increase in the number of ECHOs performed, deemed as "unnecessary" by their group, but agreed to proceed with the project implementation with the promise of monitoring for notable increases. If the CPG had been universally applied in the PrIP, only four additional ECHOs (in two months) would have been performed. Infants will be tracked for an additional six months to determine if there is a significant increase in the number of ECHOs performed and determine if any changes to the pathway should be made through rapid-cycle (PDSA) adjustments (IHI, 2020).

A sustainability plan was also created with quarterly random chart reviews and annual competency assessments administered by nursing management. The post educational assessment 
will be repeated at six months following the CPG implementation and compared to previous post educational assessments to assess retention of knowledge and any changes in nursing perceptions but extends beyond the limits of reporting for this project. The risks and unintended consequences included: concerns for missing congenital heart disease (CHD) if the CCHD practice for altitude adjustment was included in the $\mathrm{CPG}$, and disproportionately increasing the number of echocardiograms with associated costs and cardiologist time demands to read the studies. An additional unintended consequence was the potential for increased nursing stressors associated with change fatigue related to many new processes added during the expansion project.

A nursing test of knowledge and current engagement rating was distributed to staff in the nurseries on both campuses and returned to the project manager. Implementation of the project began with educational offerings for nursing staff and providers. The project manager created the educational presentations and nursing assessments for this project. These materials were reviewed by the nursing management and DNP mentor for content, clarity, and validity. The knowledge test was repeated following the education presentation to document any knowledge gained.

\section{Application of the Iowa Model}

Since it is currently in use at the organization where the project took place, the Iowa Model was chosen for this project. This model provides a step-by-step process for implementing evidence-based practice, applicable to both the novice and the expert, and expands on what is considered evidence and how to determine if practice changes are indicated (Iowa Model Collaborative, 2017). Most importantly, the model addresses the sustainability of EBP changes 
that improve outcomes to support evidence at the bedside. The steps of the model and their applicability for this project follow.

\section{Identify Triggering Issues, Opportunities}

As previously noted, the concept for this project began with the identification of several gaps in practice. An analysis of the strengths, weaknesses, opportunities, and threats (SWOT) of the practice environment was conducted and documented (see Appendix E). Nurses and providers identified practice variations and expressed concerns for patient safety during an organizational transition. Nurses further expressed increased work-related stress related to inconsistencies in practice for this population.

\section{State the Question or Purpose, Decide Priority}

The question, posed in PICOT format, was: for term and late preterm infants requiring oxygen following delivery and beyond transition, does an evidence-based practice guideline with nursing education and provider practice advice compared to traditional practice without a guideline, provide evidence-based care, support the mother-infant dyad, and impact nursing perceptions related to consistency? During a pediatric hospitalist provider retreat, the need to address the gap in practice was identified, and a consensus decision was made to have a workable solution within six months. The unit's nursing management agreed to the timeline and acknowledged the priority for completion.

\section{Form a Team}

With interprofessional collaboration in mind, stakeholders were identified as previously noted. An email questionnaire was sent during week one to the other Level I newborn nurseries within the hospital system to identify current practices and whether a similar guideline was already in place. Preliminary meetings with stakeholders during the first two weeks established 
the direction for the evidence search and current practice. Meetings with nursing management and hospital quality during the first month provided an opportunity for introductions and networking for the project. Existing relationships with providers were exploited throughout the project development phase for discussions and information gathering.

Assemble, Appraise, and Synthesize Body of Evidence, Decide Adoption into Practice

An exhaustive search for evidence is detailed in a previous section and noted on the PRISMA diagram (see Figure 1). The organization's research librarian also offered input to guide an effective search. The evidence gathered is noted on the evidence tables with grading for strength (see Appendices A \& B). The literature synthesis and practice recommendations also supported this step for the model. The organizational and geographical changes made within the last year led to several administrative structural reforms, including the creation of the Women and Infants Service Line (WISL). The project was presented at the monthly WISL meeting to inform the appropriate stakeholders about the project. The topic was then referred to the Neonatal Safety and Quality (NSQ) Committee for review and implementation approval. This multidisciplinary group comprises pediatric, neonatal, obstetrical, perinatal, emergency providers, advanced practice nurses, respiratory therapists, nursing, and management representation for each of these areas.

\section{Integrate and Sustain the Practice Change}

The DNP mentor/organizational research scientist provided critique throughout the development of this project and the proposal. The project manager requested a peer review of the CPG from the pediatric hospitalist group and nursing management within the unit before implementation. Distributing the nursing educational offering began the implementation phase of the model. Nursing knowledge and perceptions were assessed at two points after the practice 
change. Final review of the project and results will be brought to the NSQ committee at the conclusion of the project for permanent inclusion in practice approval. The CPG will become part of nursery policy, included in new employee orientation, and incorporated in annual nursing competencies per unit management's request as evidence for sustainability.

\section{Disseminate Results}

This project will be submitted to the SOAR and Sigma repositories as part of the USAHS DNP program. Results will also be presented as a poster within the organization as part of the evidence-based mission for the hospital. Other avenues for publication are detailed in the Dissemination section.

\section{Budget and Timeline}

As a DNP scholarly project, most project costs (see Table 1) were included as a student meeting requirements for the program. The nursing educational offering was offered as a prerecorded Microsoft PowerPoint presentation. To encourage staff engagement, the project manager elected to provide a small token to affix to staff badges that designated completion of the guideline training, specifically a red glitter bow. Additionally, nursery nurses and staff champion volunteers were given a more permanent badge attachment to identify them as a resource for the CPG, specifically a pair of ruby slippers. The costs for these items were nominal and were absorbed by the project manager. If the nursing management elects to continue providing these items for future hires, then they will absorb the costs. A project schedule is included in a Gantt chart (Appendix F).

\section{Leadership}

Leadership is an essential element of the Doctor of Nursing Practice program. Rather than increasing clinical expertise, the knowledge gained prepares the nurse practitioner for an 
organizational-level perspective (Doctor of Nursing Practice DNP, 2020). Bringing evidencebased practice to the bedside actively demonstrated the accomplishment of this goal.

As a part of the newborn care team, nurses and providers must have open, effective communication. Nurses demonstrated this awareness as they explored their new roles during the organization's transition and brought their concerns forward. By establishing the gap in care and acknowledging concerns, nursing staff reported they eagerly anticipated a CPG to safely care for their patients. As stakeholders, input from the nursing staff was regularly elicited in making patient care decisions to enhance engagement with leadership from the project manager.

As the provider education for implementing the project was delivered for the final approval vote, the neonatology physician representative for the section objected to the echocardiogram practice recommendations in the CPG. The project manager made patient care and outcomes the priority, agreed to delay the section vote, and rapidly gathered the requested data. An email with the requested information was drafted and sent to the neonatology group with a plan for an electronic vote within the week. Although this delay might have impacted the student's degree plan, a demonstration of leadership and perseverance enabled deadline completions with a minor implementation delay.

\section{Evaluation Results}

The CPG was implemented as an EBP project and applied to all newborns admitted to the North and Central nurseries requiring oxygen following delivery. Infants admitted to the nursery and placed on oxygen during two randomly selected months before the project started were analyzed and determined the practice recommendations included in the final CPG. Infants who did not require oxygen during their initial hospital stay were excluded from the analysis. Infants who transferred to NICU were noted for safety tracking but did not permit full data collection 
and were excluded from reporting. Data analysis continued monthly until the project's completion when CPG ownership, data retrieval, and analysis were surrendered to nursing management.

\section{Measures}

This project collected two data sets for analysis. The first data set included term and late preterm infants requiring oxygen following delivery (see Appendix G) and assessed the efficacy of the CPG and infant safety. The second data set addressed the nursing staff caring for these infants (see Appendix H). This data assessed knowledge acquisition and nursing perceptions for engagement. The project manager performed all data collection and analysis. The CPG education and nursing assessments will be included in annual nursing competencies as a measure of sustainability.

\section{Population}

In the pre-implementation phase (PrIP) for this project, 656 infant electronic medical records were reviewed, with 39 infants on oxygen included in the analysis. The postimplementation phase (PoIP) was limited to 441 records, with 32 infants included in the analysis. Due to time limits for completing this project per university guidelines, the PoIP data collection was decreased to four weeks instead of the eight weeks utilized in the PrIP and slightly impacted the size of the population of interest for this phase.

All nursery and mother-baby nurses employed in August 2020 at the organization participated in the virtual education. The education and assessments were made mandatory by nursing management to optimize reporting fidelity. Nursing responses included 106 for the preimplementation assessment and 62 for the first post-implementation assessment. A 
SurveyMonkey ${ }^{\circledast}$ question was added to the educational offering to track completion of the presentation with 90 responses.

\section{Comparative Data}

A review of the electronic medical records (EMR) for all term and late preterm infants determined those infants requiring oxygen following delivery. Those born during January and February 2020 established the PrIP. Beginning on the implementation date, infants requiring oxygen following delivery became the PoIP. Interim analyses during the first four weeks of the PoIP were performed weekly to identify any concerning trends for infant safety.

Nursing data points were collected and analyzed using SurveyMonkey ${ }^{\circledR}$ software to gather demographic information, assess knowledge acquisition, and engagement perceptions. The knowledge questions highlighted the practice recommendations addressed in the CPG. The pre-educational assessment (Appendix I) was administered two weeks before the nursing educational offering was distributed. The post-educational assessment included the same questions eliminating the demographic information and was distributed four weeks after the nursing education.

\section{Data Accuracy}

The EMR for each patient on the PrIP data list generated by the quality manager was presumed accurate for every infant born during the randomly chosen period. The PoIP patient list was compiled weekly from existing nursery patient logs. A patient list from the quality manager was used to verify the accuracy of the patient logs and account for missed collection days. Nursing assessments were tracked using the SurveyMonkey ${ }^{\circledR}$ software. All data points were entered into the SPSS tool by the project manager and verified for accuracy.

\section{Collection and Storage}


The project manager retrieved infant data from the EMR using medical record numbers (MRN) generated from the quality manager's lists. The file was secured in a locked drawer onsite at the North campus. Cross-referencing with pediatric cardiology for any missed CHD in the PrIP was done via secure email. The nursery census for the PoIP was collected daily and placed in a folder located in each of the nurseries during the first four weeks following implementation. The SPSS datasheets, explicitly created with HIPAA considerations, were stored on the project manager's laptop. All data relating to the project was permanently deleted from the device once the CPG ownership was surrendered to nursing management.

\section{Privacy of Information}

Patient data was de-identified during collection and storage to protect privacy using infant birthdate as the principal identifier with birthweight as a secondary identifier for duplicate dates. Nursing data was analyzed by the SurveyMonkey ${ }^{\circledR}$ software with aggregate reporting to protect staff anonymity. No lists linking individual staff and their responses were collected or maintained.

\section{Statistical Analysis}

The newborn data table (see Appendix G) and nursing data table (see Appendix H) detail the information collected for the project. The information to determine data points was assembled from project exemplars (Lueth et al., 2016; Paranka et al., 2018) and statistics course text by Andy Field (2018). A research statistician from the target organization was also consulted for data analysis advice.

The PrIP included 659 infants, 39 required oxygen beyond the delivery room. The PoIP included 441 babies, 32 required oxygen beyond the delivery room. The frequency of collected 
characteristics for both groups are displayed as aggregate data in Table 2 . These data were not assessed for significance as they were not included in the PICOT question.

Nursing demographics for gender, age, education, and experience were collected for potential future reporting and displayed in Table 3. SPSS software was utilized with paired samples $t$-tests for the questions in the nursing assessments. Results for individual question responses are presented as means with standard deviations $( \pm \mathrm{SD})$ for significance (see Table 4$)$. Of note, only question one and question three demonstrated statistically significant differences in nursing knowledge.

\section{Understanding Data Variations}

Limited informational access prevented a planned additional comparative data collection from evaluating potential variations added during the development of this project and is acknowledged as a limitation. An additional risk for information overload for nursing staff associated with the new unit opening and frequent COVID-19 pandemic updates and practice changes were acknowledged as potentially impacting the success or failure of the project.

\section{Ethical Considerations}

A project proposal was submitted to the USAHS Evidence-Based Practice Project Review Council (EPRC) per university requirements and approved. As an evidence-based practice change, no formal IRB approval was required by the target organization. The project was, however, reviewed and approved with reporting suggestions by the Director of IRB Administration for the organization. Additionally, a project proposal submission to the organization's Evidence-Based Practice Council was required to ensure the safety of patients and participants. Approval for the CPG implementation was granted with formal noticiation via email. 


\section{Impact}

As an outcomes-based EBP project implementing a CPG for administering oxygen in the newborn nursery, this project was an example of an evaluative analysis (White et al., 2016). In a series of articles, Ranganathan et al. (2015) framed the difference between statistical and clinical significance. With its limited population of interest, this project never achieved the definition of statistical significance but did attain several measures of clinical significance. Clinical significance, determined via clinical judgment rather than statistical analysis, was characterized by Raganathan et al. (2015) as more challenging to define.

During initial considerations, it was predicted that the hospitalist providers would choose to accept passing the CCHD on LFNC at $\leq 60 \mathrm{~mL}$ as an acceptable flow, not requiring a baseline ECHO; the practice recommended and utilized by the neonatology group. With the evidence recommending an ECHO for any oxygen at the time of screen (an indeterminate screen), it was concluded that the recommendation should include an ECHO for infants on any LFNC at the time of CCHD screen. The pediatric cardiology providers' preference for a baseline ECHO for all infants with an indeterminate CCHD screen also supported this concept. Although the pediatric hospitalists had some practice variability, many providers in the group had already been following this pathway. The group agreed this was a reasonable, safe, and clinically significant option for practice.

The number of infants on LFNC before or at the CCHD screen before and after implementation was relatively equal and created a reasonable comparison for both groups. The PoIP demonstrated an increase in the number of ECHOs performed, 16 compared to four in the PrIP for raw scores (see Table 5). At first blush, this number appears to confirm the neonatologist's concerns for unnecessary tests. Upon further investigation, however, a limitation 
of the project was observed. The PoIP infants were not simultaneously tested for the ability to pass the CCHD on LFNC. It was impossible to determine if an ECHO would have been indicated regardless of the CPG pathway and may have impacted the significance of this comparison. This omission was presented at Neonatal Safety and Quality and submitted to the Evidence-Based Practice Review Council as a rapid cycle improvement revision for future data review.

No infants in the PrIP were identified as having abnormal ECHO results for age or having a missed congenital heart disease while the provider practice variability remained. This evidence could have supported including the LFNC altitude adjustment in the CPG. Recalling that several providers were already ordering an ECHO for an indeterminate CCHD screen, the clinical significance is not as clear. In the PoIP group, one infant was identified as having a ventricular septal defect (also noted on a prenatal ultrasound), and two infants demonstrated persistent pulmonary hypertension of the newborn. These two infants were subsequently treated with oxygen and had normal ECHOs for age at discharge. One of these infants was evaluated by a provider who would have obtained an ECHO and one by a provider who would not have obtained an ECHO if the infant had passed the CCHD screen on LFNC. Although no determination if these infants (PoIP) would have passed CCHD on LFNC was made, it may be reasonable to predict these infants might have been "missed" if an ECHO had not been obtained. Considering the pathophysiology and potential for decompensation noted previously, these infants may have worsened if discharged without treatment. They may have also required rehospitalization with enhanced/escalated care, demonstrating more clinical significance for the project pathway. 
With nursing empowerment as an outcome for this project, the data appeared to show statistical significance for the measures noted in Table 6 . A direct reference to nursing empowerment, question one, improved following the CPG implementation. What may be more critical, however, is the high rate of empowerment expressed by nurses before this EBP project asked the question. Nurses in practice at this organization felt enabled to give input, with

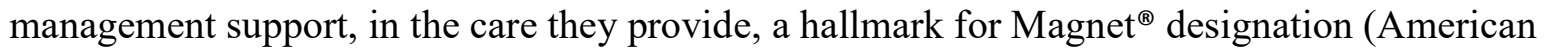
Nurses Credentialing Center, 2020). The project also established a channel for nurses to bring future concerns forward in an atmosphere of collegial practice to provide the best evidence-based care for optimal patient outcomes.

Another query for confidence to approach providers, as a measure of engagement, also demonstrated improvement. Although the participant numbers are too small to show true statistical significance, the clinical practice value cannot be ignored (Raganathan et al. 2015). Patients benefit when the staff providing their care are engaged. The Lean principles detailed by Mark Graban (2016) included many examples of improved patient outcomes directly associated with employee engagement.

Another limitation of this project was the lack of paired comparisons created by the decision to utilize SurveyMonkey ${ }^{\circledR}$ assessments. This product was recommended by nursing management, given the format familiarity to the staff. Data could not be collected or reported to measure individual knowledge or empowerment changes, only as aggregates. Consideration for further exploration could be an individual assessment of these perceptions through structured interviews. As an additional note for clinical significance, the educational offering presented empowerment and engagement issues and was anecdotally reported to impact staff discussions positively. 


\section{Plans for Dissemination}

At the organizational level, the project results will be presented to the Evidence-Based Practice Review Committee during the January 2021 meeting. This organization is also on the journey toward achieving Magnet ${ }^{\circledR}$ status. The DNP mentor determined that this project may also be included as part of the organization's application process. Lastly, the project will be submitted to the $32^{\text {nd }}$ Rocky Mountain Research and Evidence-Based Symposium.

This EBP change project is planned for submission to the Academy of Neonatal Nursing national conferences. Each conference has subsections dedicated to either neonatal intensive care/advanced practice nurses or mother-baby nurses. A poster presentation will be submitted to the mother-baby nurses' conference. Each submission is blind, peer-reviewed for consideration by a minimum of three neonatal nurses. The poster abstracts are then published in the conference proceedings section of Neonatal Network ${ }^{\circledR}$ : The Journal of Neonatal Nursing, following each conference. The final project will further be submitted for the following ANNTM conference as a podium presentation for the neonatal/advanced practice nurses conference with a greater focus on the DNP educational experience.

The project was prepared for submission to the institutional repository at SOAR@USA to meet the university's requirements and will be submitted in compliance with the established timeline for the course. An additional optional submission to the Sigma Theta Tau International repository is also planned. At the suggestion of clinical faculty, the project will also be submitted to the Doctor of Nursing Practice repository at https://www.doctorsofnursingpractice.org/. As a clinical issue in neonatal care, submission for publication in Advances in Neonatal Care, the journal published by the National Association of Neonatal Nurses (NANN), will also be considered. 


\section{Conclusion}

All infants undergo many physiological changes during the transition to life outside the uterus, and the majority of term and late preterm infants do so with relative ease. Some infants, however, require additional support to make these changes, including extra tactile stimulation, provision of supplemental oxygen, or full resuscitation, including chest compressions. Being born at higher altitudes increases the likelihood an infant will require supplemental oxygen during transition and beyond, the "altitude adjustment" referred to in some literature. However, what was not clear is how much oxygen and the impact oxygen administration should have on routine screens, such as the CCHD screening, now required before hospital discharge across the country.

Practice consistency, through clinical practice guidelines and pathways, is well-supported in the literature across many disciplines. A shared-practice model guideline developed to meet the needs of infants requiring supplemental oxygen was the focus of this EBP project. With retrospective, comparative data, a recommendation for practice was proposed with plans to follow infant safety and quality of care using the new pathway in a novel approach to neonatal care at moderate altitude. Proposing consensus practice recommendations, found in the CCHD screen evidence, consistently ensured infant safety for optimal outcomes.

Comparing nurse perceptions for nursing engagement and empowerment was an additional aim of this project. Rather than being merely physician extenders, bedside nurses and nurse leaders have continued to emerge as partners in care at the bedside over several decades. Engaging nurses in bringing evidence-based practice to the bedside universally impacts outcomes for patients. Empowering nurses in practice enhances the foundation for moving nursing forward in 2020, The Year of the Nurse. 


\section{References}

American Academy of Pediatrics. (2012). Levels of neonatal care. Pediatrics, 130(3), 587-597. https://doi.org/10.1542/peds.2012.1999

American Association of Colleges of Nursing. (n.d.). DNP essentials. Retrieved October 5, 2020, from https://www.aacnnursing.org/DNP/DNP-Essentials

American Nurses Credentialing Center. (n.d.). Magnet recognition. Retrieved January 10, 2020, from https://www.nursingworld.org/organizational-programs/magnet/

Centers for Disease Control and Prevention. (2018). Congenital heart defects (CHD) information for healthcare providers. https://www.cdc.gov/ncbddd/heartdefects/hcp.html

Colorado Springs Chamber \& EDC. (n.d.). Doing business: Demographics. Retrieved January 12, 2020, from https://coloradospringschamberedc.com/doing-business/demographics/

Császár-Nagy, N., \& Bókkon, I. (2018). Mother-newborn separation at birth in hospitals: A possible risk for neurodevelopmental disorders? Neuroscience and Biobehavioral Reviews, 84, 337-351. https://doi.org/10.1016/j.neubiorev.2017.08.013

Dang, D., \& Dearholt, S. (2018). Johns Hopkins Nursing Evidence-Based Practice: Model and Guidelines ( $3^{\text {rd }}$ ed.). Sigma Theta Tau International.

Department of the Army. (2002). Military mountaineering: Field manual 3-97.61. Military Mountaineering. https://www.globalsecurity.org/military/library/policy/army/fm/3-97$\underline{\text { 61/index.html }}$

Doctor of Nursing Practice DNP. (n.d.). The unique contributions of DNP-prepared nurse practitioners and other APRNs. Retrieved February 2, 2020, from https://www.doctorofnursingpracticednp.org/the-role-of-dnp-educated-nurses-inadvanced-clinical-practice/ 
Dols, J., Muñoz, L., Martinez, S., Mathers, N., Miller, P., Pomerleau, T., Timmons, A., \& White, S. (2017). Developing policies and protocols in the age of evidence-based practice. Journal of Continuing Education in Nursing, 48(2), 87-92. https://doi.org/10.3928/00220124-20170119-10

Field, A. (2018). Discovering statistics using IBM SPSS statistics, North American edition (5 ${ }^{\text {th }}$ ed.). Sage Publications, Inc.

Graban, M. (2016). Lean hospitals: Improving quality, patient safety, and employee engagement ( $3^{\text {rd }}$ ed.). CRC Press.

Gray-Toft, P., \& Anderson, J. (1981). The nursing stress scale: Development of an instrument. Journal of Behavioral Assessment 3, 11-23. https://doi.org/10.1007/BF01321348

Grazel, R. (2018). Screening for CCHD with pulse oximetry: Where are we now? http://nann.org/publications/e-news/november2018/special-interest-group

Gonzalez-Andrade, F., Echeverria, D., Lopez, V., \& Arellano, M. (2018). Is pulse oximetry helpful for the early detection of critical congenital heart disease at high altitude? Congenital Heart Disease, 13(6), 911-918. https://doi.org/10.1111/chd.12654

Hooper, S. B., Roberts, C., Dekker, J., \& te Pas, A. B. (2019). Issues in cardiopulmonary transition at birth. Seminars in Fetal and Neonatal Medicine, 24(6). https://doi.org/10.1016/j.siny.2019.101033

Institute for Healthcare Improvement. (n.d.). Science of improvement: Testing changes. Retrieved January 10, 2020, from http://www.ihi.org/resources/Pages/HowtoImprove/ScienceofImprovementTestingChang $\underline{\text { es.aspx }}$ 
Institute of Medicine. (1999). To err is human: Building a safer health system.

http://nationalacademies.org/hmd/ /media/Files/Report\%20Files/1999/To-Err-isHuman/To\%20Err\%20is\%20Human\%201999\%20\%20report\%20brief.pdf

Institute of Medicine. (2001). Crossing the quality chasm: A new health system for the 21st century. http://nationalacademies.org/hmd/ /media/Files/Report\%20Files/2001/Crossingthe-Quality-Chasm/Quality\%20Chasm\%202001\%20\%20report\%20brief.pdf

Iowa Model Collaborative. (2017). Iowa Model of evidence-based practice: Revisions and validation. Worldviews on Evidence-Based Nursing, 14(3), 175-182. https://doi.org/10.1111/wvn.12223

Jaafar S., Ho J., \& Lee K. (2016). Rooming-in for new mother and infant versus separate care for increasing the duration of breastfeeding. Cochrane Database of Systematic Reviews 2016, (8). Art. No.: CD006641. https://doi.org/10.1002/14651858.CD006641.pub3

Kayton, A., Timoney, P., Vargo, L., \& Perez, J., P. (2018). A review of oxygen physiology and appropriate management of oxygen levels in premature neonates. Advances in Neonatal Care, 18(2), 98-104. https://doi.org/10.1097/ANC.0000000000000434

Lakshminrusimha, S., Konduri, G., \& Steinhorn, R. (2016). Considerations in the management of hypoxemic respiratory failure and persistent pulmonary hypertension in term and late preterm neonates. Journal of Perinatology, 36, S12-S19. https://doi.org/10.1038/jp.2016.44

Lewin, K. (1951). Field theory in social science: Selected theoretical papers (D. Cartwright, Ed.). Harper \& Row. https://doi.org/10.1177/000271625127600135

Lueth, E., Russell, L., Wright, J., Duster, M., Kohn, M., Miller, J. Eller, C. Sontag, M. \& Rausch, C. (2016). A novel approach to critical congenital heart disease (CCHD) 
screening at moderate altitude. International Journal of Neonatal Screening, 2, 4. https://doi.org/10.3390/ijns2030004

Moran, K., Burson, R., \& Conrad, D. (Eds). (2020). The doctor of nursing practice project: A framework for success ( $3^{\text {rd }}$ ed.). Jones \& Bartlett Learning.

Melnyk, B., \& Fineout-Overholt, E. (2015) Evidence-based practice in nursing \& healthcare: A Guide to Best Practice ( $3^{\text {rd }}$ ed.). Wolters Kluwer.

National Eye Institute. (n.d.). Retinopathy of prematurity. Retrieved December 10, 2019, from https://www.nei.nih.gov/learn-about-eye-health/eye-conditions-and-diseases/retinopathyprematurity

Olswang, L. B., \& Goldstein, H. (2017). Collaborating on the development and implementation of evidence-based practices: Advancing science and practice. Evidence-Based Communication Assessment Intervention, 11(3-4), 61-71. https://doi.org/10.1080/17489539.2017.1386404

Paranka, M. S., Brown, J. M., White, R. D., Park, M. V., Kelleher, A. S., \& Clark, R. H. (2018). The impact of altitude on screening for critical congenital heart disease. Journal of Perinatology, 38, 530-536. https://doi.org/10.1038/s41372-018-0043-9

Perrone, S., Bracciali, C., Di Virgilio, N., \& Buonocore, G. (2017). Oxygen use in neonatal care: A two-edged sword. Frontiers in Pediatrics, 4, 143. https://doi.org/10.3389/fped.2016.00143

Ranganathan, P., Pramesh, C. S., \& Buyse, M. (2015). Common pitfalls in statistical analysis: Clinical versus statistical significance. Perspectives in Clinical Research, 6(3), 169-170. $\underline{\text { https://doi.org/10.4103/2229-3485.159943 }}$ 
Titler, M., Kleiber, C., Steelman, V., Rakel, B., Budreau, G., Everett, L., Buckwalter, K., TrippReimer, T., \& Goode, C. (2001). The Iowa Model of evidence-based practice to promote quality care. Critical Care Nursing Clinics of North America, 13(4), 497-509. https://doi.org/10.1016S0899-5885(18)30017-0

Tekleab, A. M., \& Sewnet, Y. C. (2019). Role of pulse oximetry in detecting critical congenital heart disease among newborns delivered at a high altitude setting in Ethiopia. Pediatric Health, Medicine and Therapeutics, 10, 83-88. https://doi.org/10.2147/PHMT.S217987

UCHealth. (n.d.). About UCHealth. Retrieved January 20, 2020, from https://www.uchealth.org/about/

White, K., Dudley-Brown, S., \& Terhaar, M. (2016). Translation of evidence into nursing and health care ( $2^{\text {nd }}$ ed.). Springer Publishing.

World Health Organization. (2016). Oxygen therapy for children: A manual for health workers. https://www.who.int/maternal_child_adolescent/documents/child-oxygen-therapy/en/ 


\section{Table 1}

\section{Budget}

\begin{tabular}{|c|c|c|c|}
\hline EXPENSES & & REVENUE & \\
\hline Direct & & Billing (coding for oxygen use TBD) & \\
\hline $\begin{array}{l}\text { Salary and benefits } \\
\text { nursing education as part of regular } \\
\text { staff meeting attendance }\end{array}$ & $\mathrm{n} / \mathrm{a}$ & Grants & 0 \\
\hline $\begin{array}{l}\text { Supplies } \\
\text { pins for resource nurses, education } \\
\text { completion bows }\end{array}$ & 100 & Institutional budget support & \\
\hline Services & & $\begin{array}{l}\text { Potential reduction echocardiogram } \\
\text { billing expenses (TBD) }\end{array}$ & \\
\hline $\begin{array}{l}\text { Statistician } \\
\text { Two billable hours to develop data } \\
\text { collection tool and consult for } \\
\text { results generation }(\$ 35 / \mathrm{hr}) \text { but done } \\
\text { as part of regular work time }\end{array}$ & 70 & & \\
\hline $\begin{array}{l}\text { Indirect } \\
\text { Data mining to be performed by } \\
\text { DNP student as part of the project }\end{array}$ & & & \\
\hline Overhead & $\mathrm{n} / \mathrm{a}$ & & \\
\hline Total Expenses & $\$ 170$ & & \\
\hline Net Balance & $\$-170$ & Total Revenue & $\$ 0$ \\
\hline
\end{tabular}

Note. Format taken from a template provided by USAHS for NUR7801, 2019-2020 academic year 
Table 2

Infant Characteristics

\begin{tabular}{|c|c|}
\hline Gender & $\begin{array}{c}\% \text { total population } \\
n=71\end{array}$ \\
\hline male & 57 \\
\hline female & 43 \\
\hline \multicolumn{2}{|l|}{ Gestational Age } \\
\hline late preterm & 19 \\
\hline term & 71 \\
\hline \multicolumn{2}{|l|}{ Ethnicity } \\
\hline white, non-hisp & 57 \\
\hline black & 10 \\
\hline hispanic & 24 \\
\hline asian/native am/pac islander & 5 \\
\hline not listed & 4 \\
\hline \multicolumn{2}{|l|}{ Birth Nursery Location } \\
\hline North & 74 \\
\hline Central & 26 \\
\hline
\end{tabular}

Note. Aggregate data from infants requiring oxygen following delivery 
Table 3

Nursing Staff Characteristics

Gender

$\%$ of nursing staff employed at CPG

Total implementation

\section{male}

0

0

female

100

106

Age Range

$\begin{array}{lcc}20-30 \text { years } & 21 & 22 \\ 31-40 \text { years } & 25 & 26 \\ 41-50 \text { years } & 33 & 35 \\ 51-60 \text { years } & 13 & 14 \\ \text { over } 60 \text { years } & 8 & 9\end{array}$

Highest Degree Completed

\begin{tabular}{ccc}
\hline diploma & 4 & 4 \\
associates & 9 & 10 \\
bachelors & 80 & 85 \\
masters & 7 & 7 \\
doctorate & 0 & 0
\end{tabular}

Total Nursing Experience

$\begin{array}{rcc}0-3 \text { years } & 21 & 22 \\ 4-10 \text { years } & 35 & 37 \\ 11-20 \text { years } & 25 & 27 \\ \text { over } 20 \text { years } & 19 & 20\end{array}$

Note. Aggregate data collected from SurveyMonkey software 


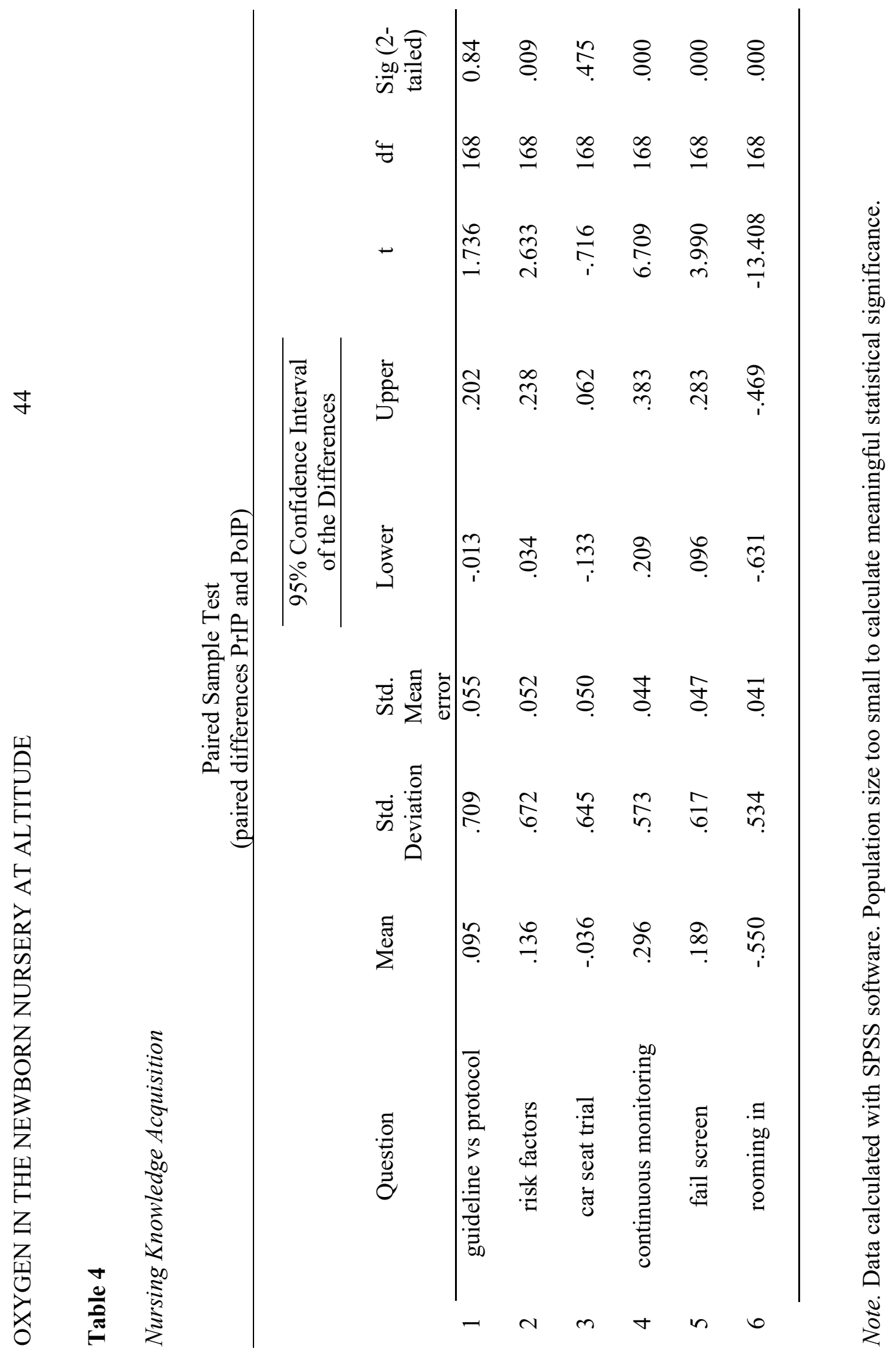




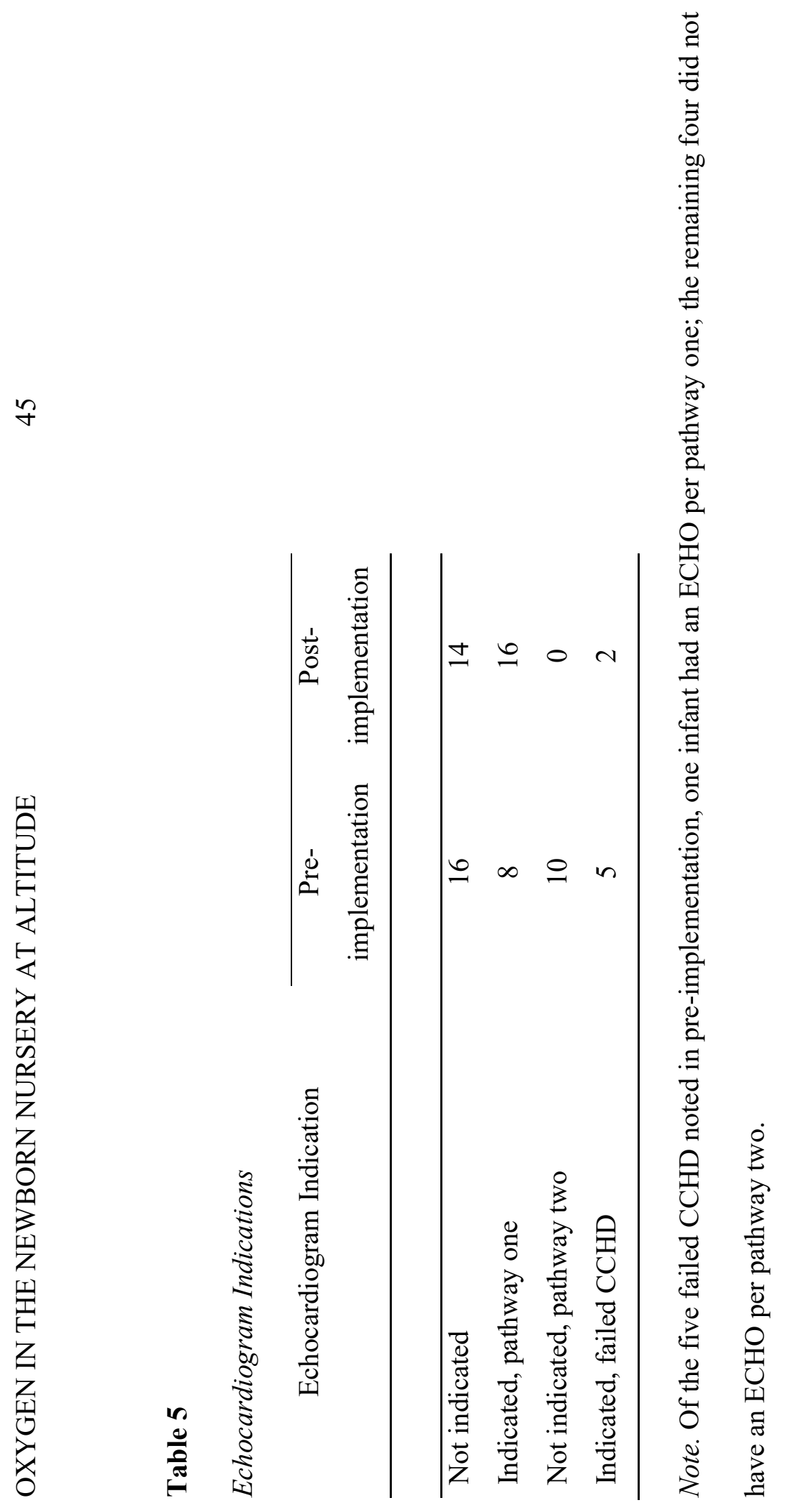




\section{Table 6}

Nursing Empowerment and Engagement

$$
\text { Question and response }
$$

$\begin{array}{cc}\begin{array}{c}\text { Before Education } \\ (\% \text { response })\end{array} & \begin{array}{c}\text { After education } \\ n=106\end{array} \\ \end{array}$

I feel empowered, as a nurse, to discuss patient care with any provider

strongly agree

agree

neither agree nor disagree

disagree

strongly disagree

38

48

9

3

2

30

2
33

59

6

2

0

33

agree

47

12

7

strongly disagree

neither agree nor disagree

disagree

1

A guideline will give me more confidence in caring for an infant on oxygen

True

99

100

False

0

0

Note. Aggregate data from nursing surveys 
Figure 1

PRISMA diagram

Records identified using newborn, oxygen and altitude ( $n=132)$

Additional records identified using CCHD and PPHN ( $n=304$ )

Records after duplicates removed $(n=405)$
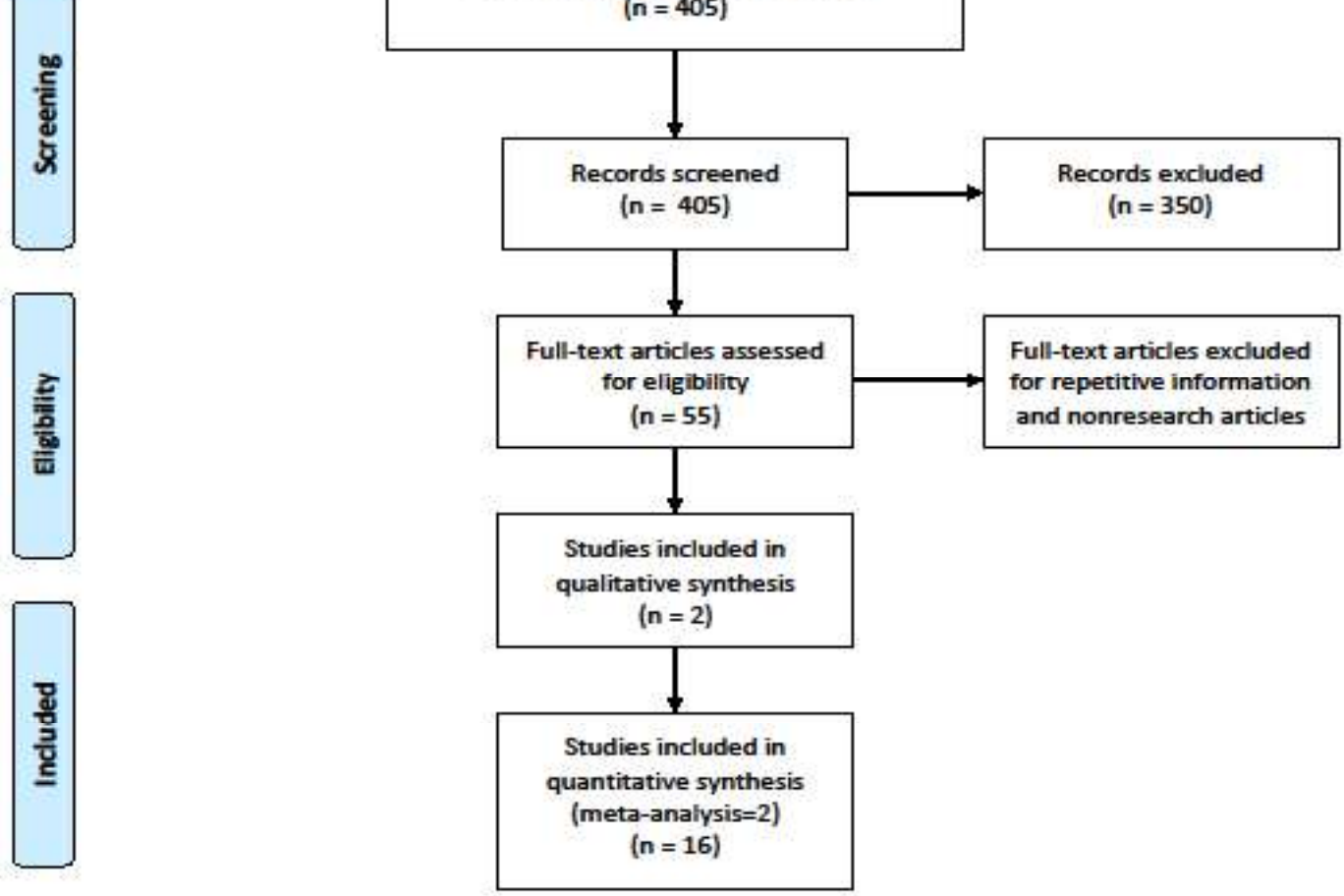

From: Moher D, Lberat A, Tetzlan J, Altman DG, The PRISMA Group (2009). Preferred Reporting hems for Systematic Revlews and MetaAnalyse6: The PRISMA Statement. PLOS Med 6(7): e1000097. dol:10.137 1/journal.pmedio00097 

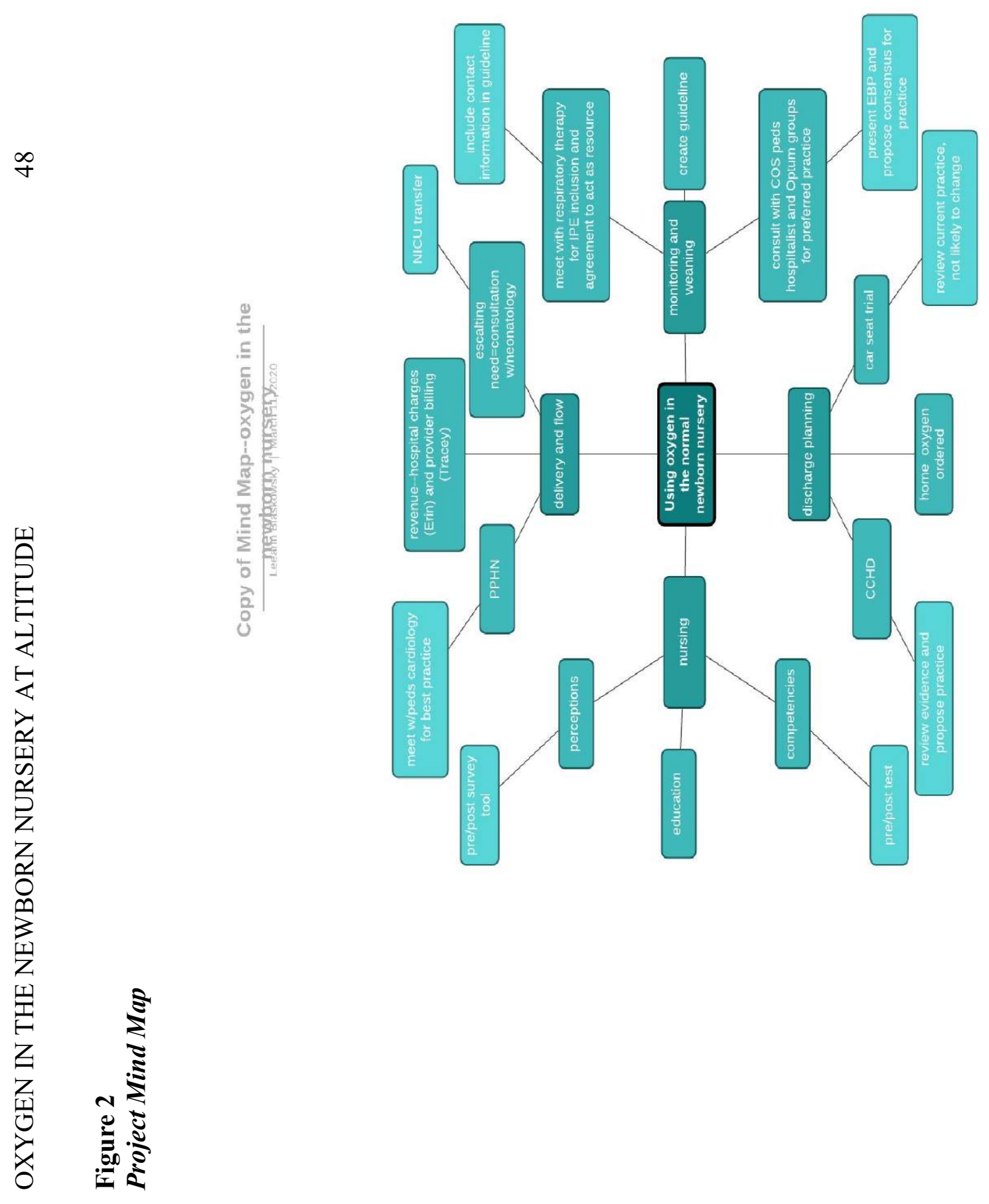


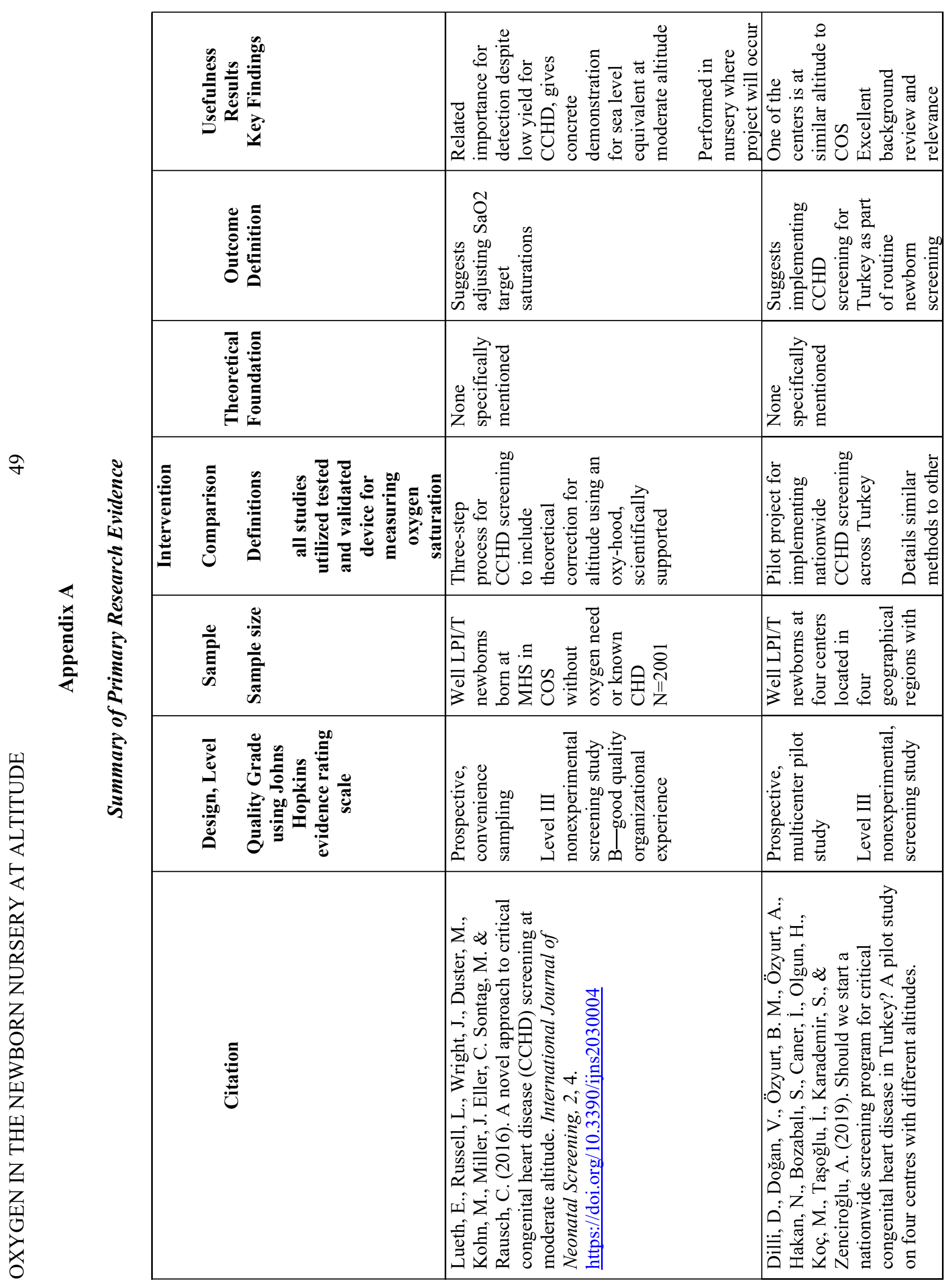




\begin{tabular}{|c|c|c|}
\hline 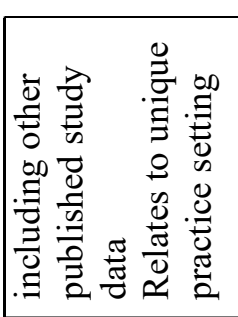 & 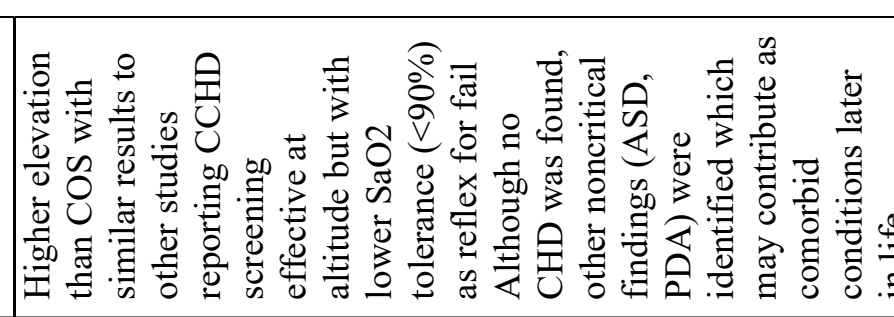 & 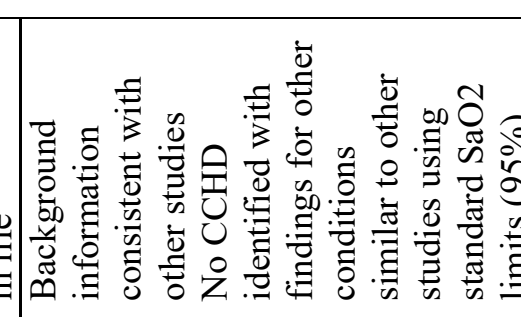 \\
\hline & 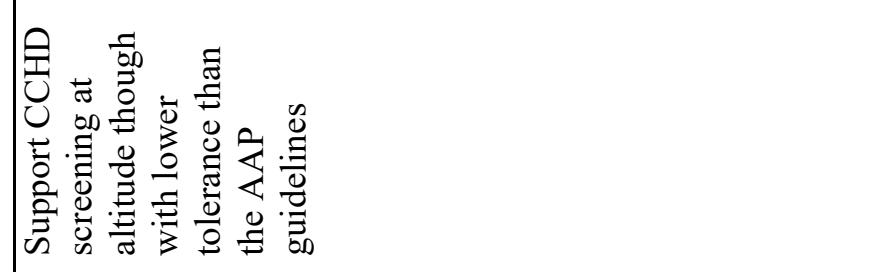 & 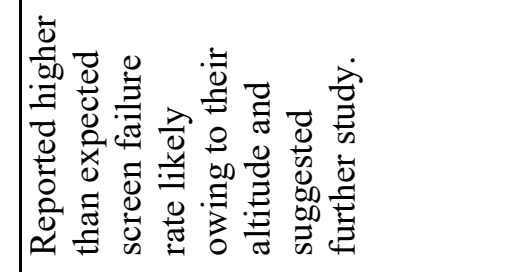 \\
\hline & 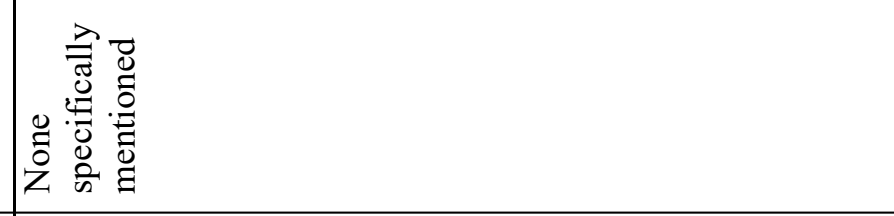 & 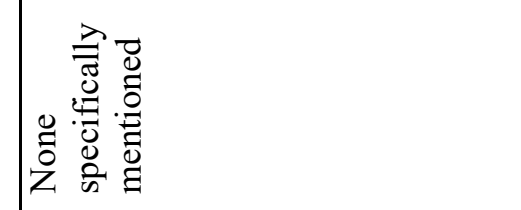 \\
\hline 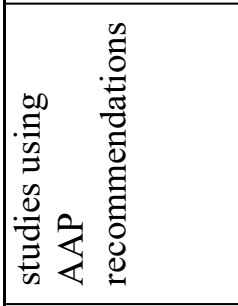 & 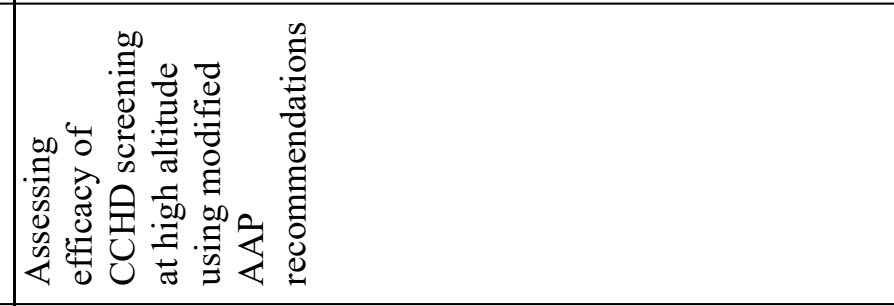 & 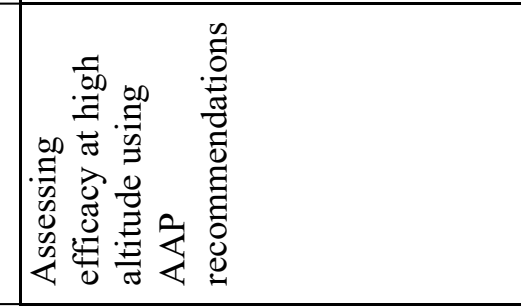 \\
\hline 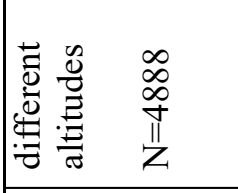 & 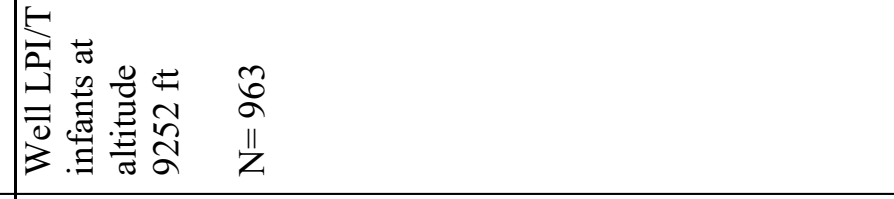 & 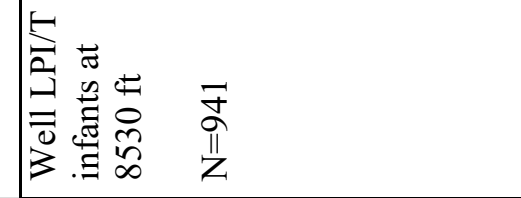 \\
\hline 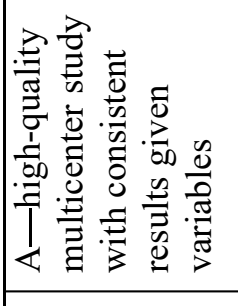 & 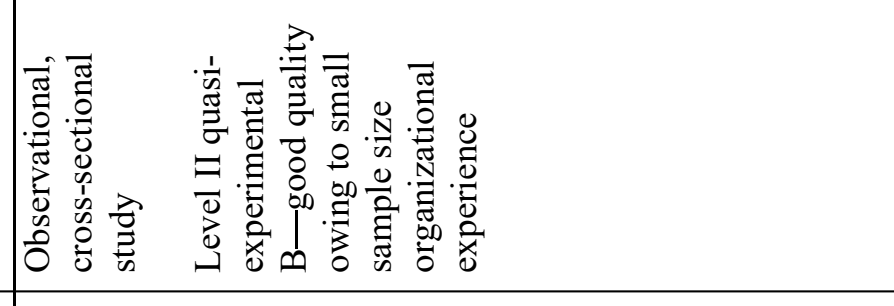 & 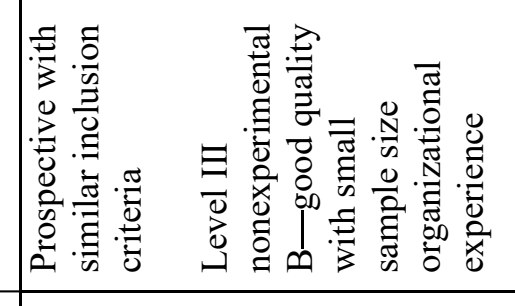 \\
\hline 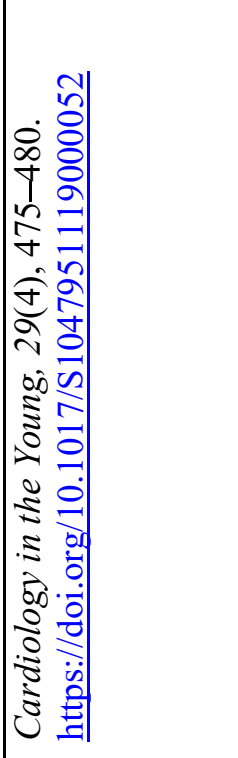 & 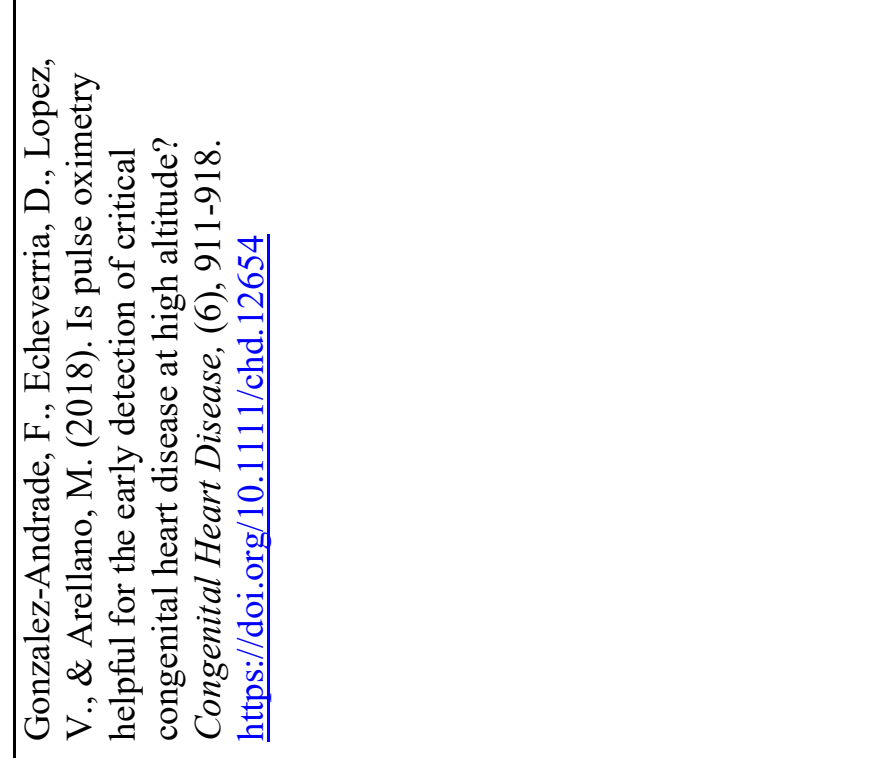 & 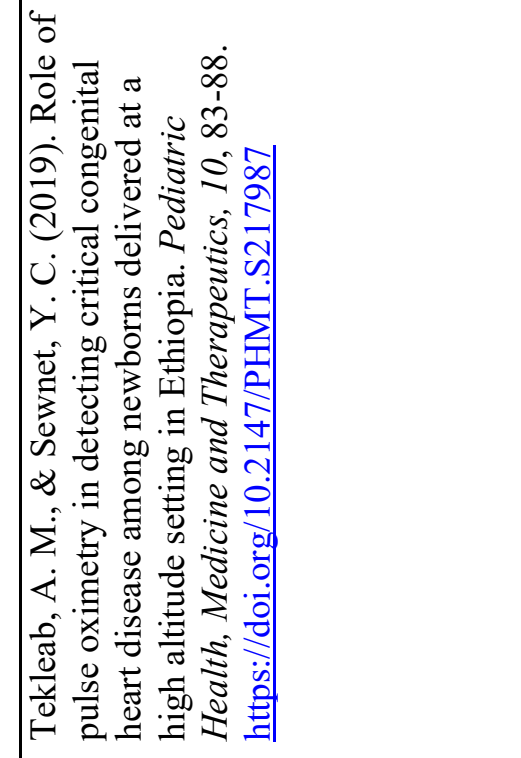 \\
\hline
\end{tabular}




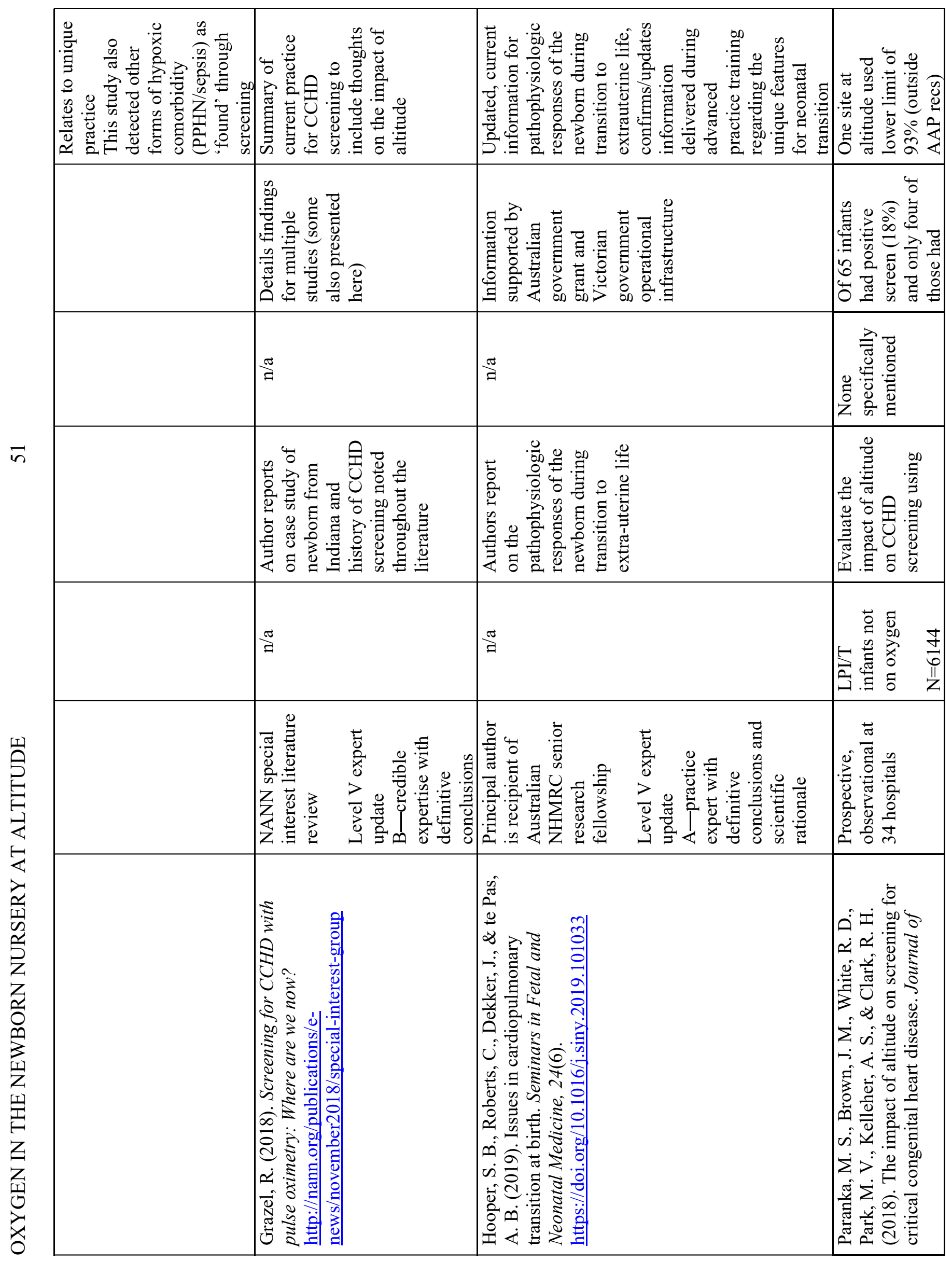




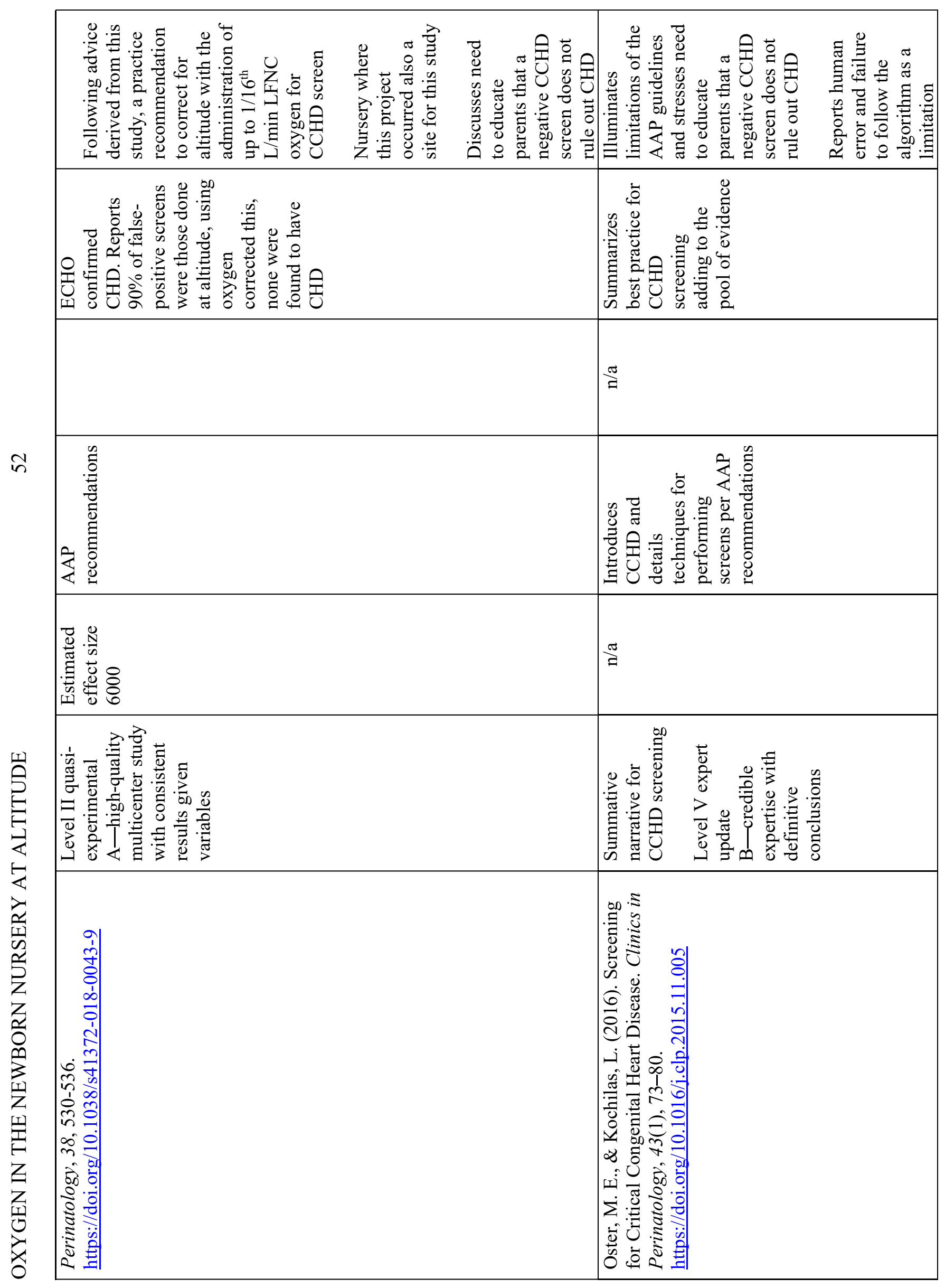




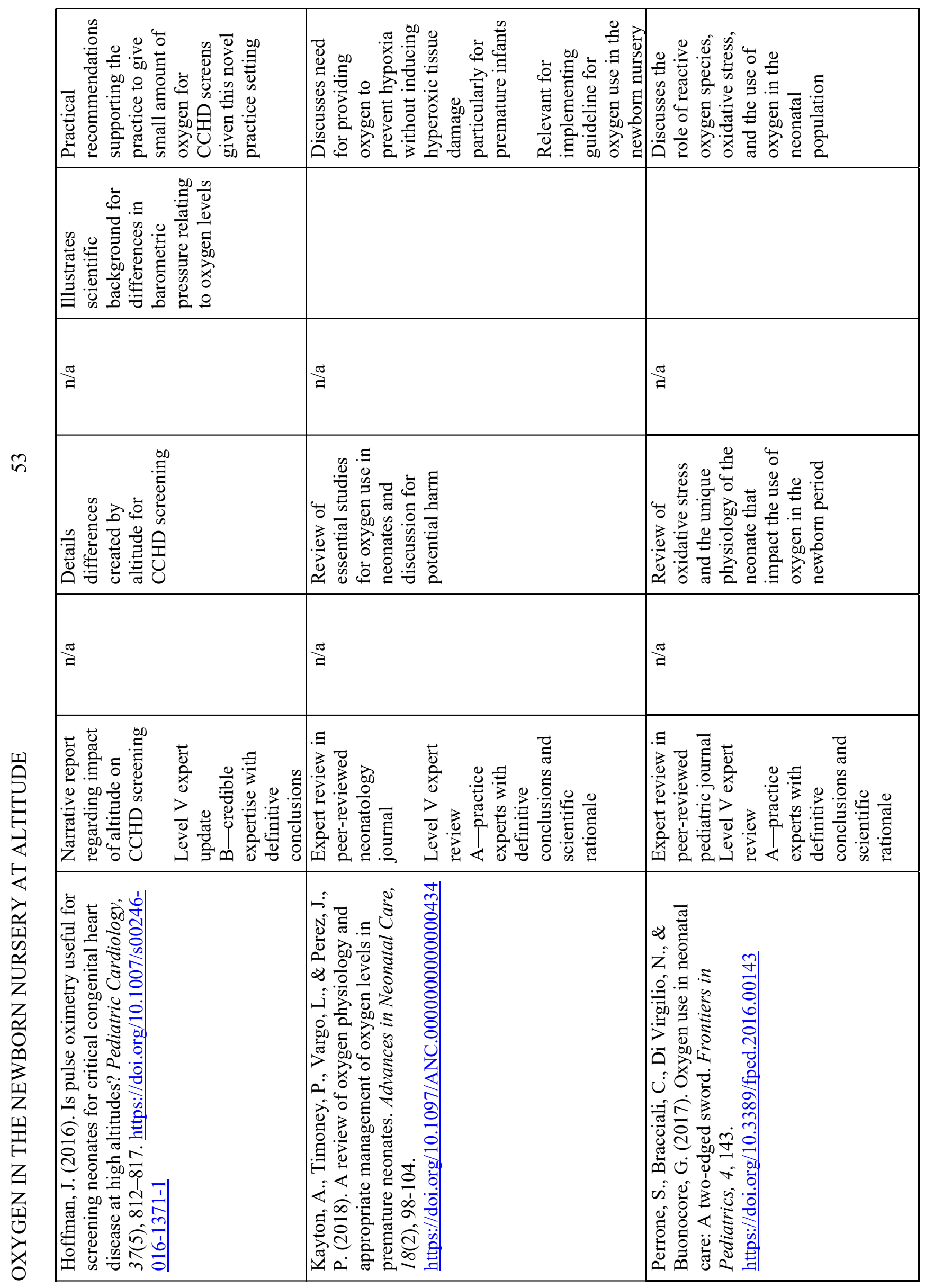




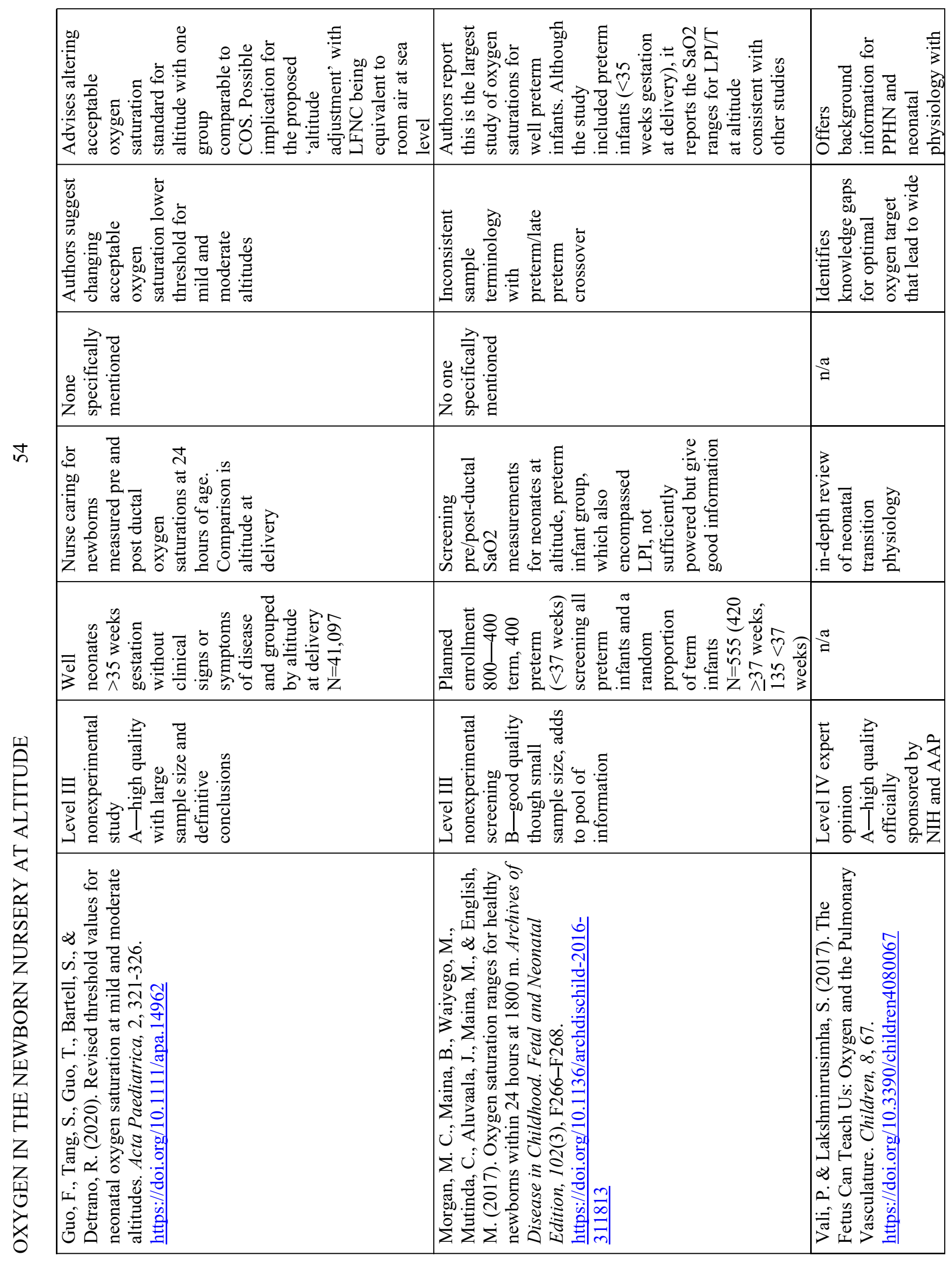




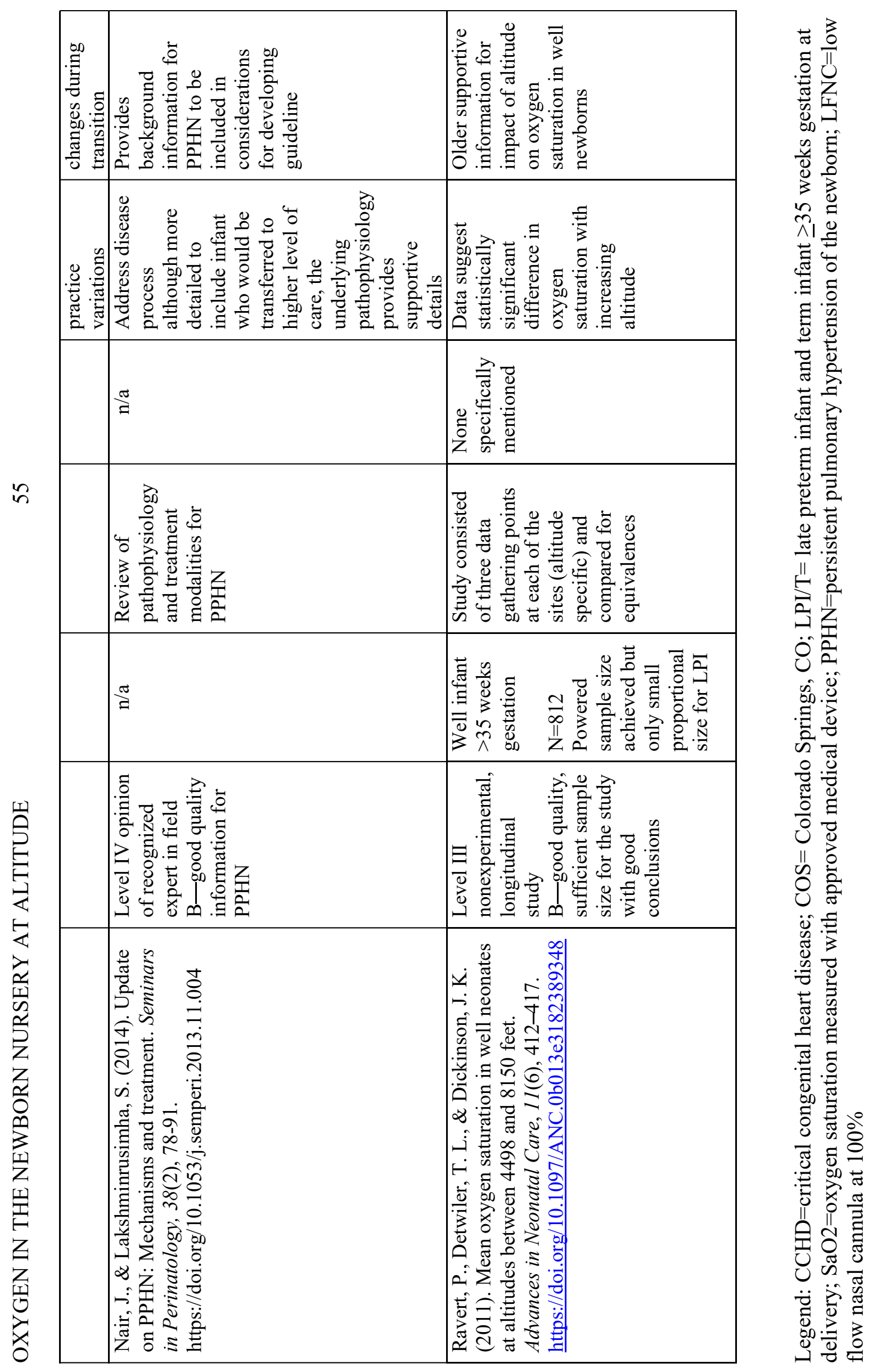




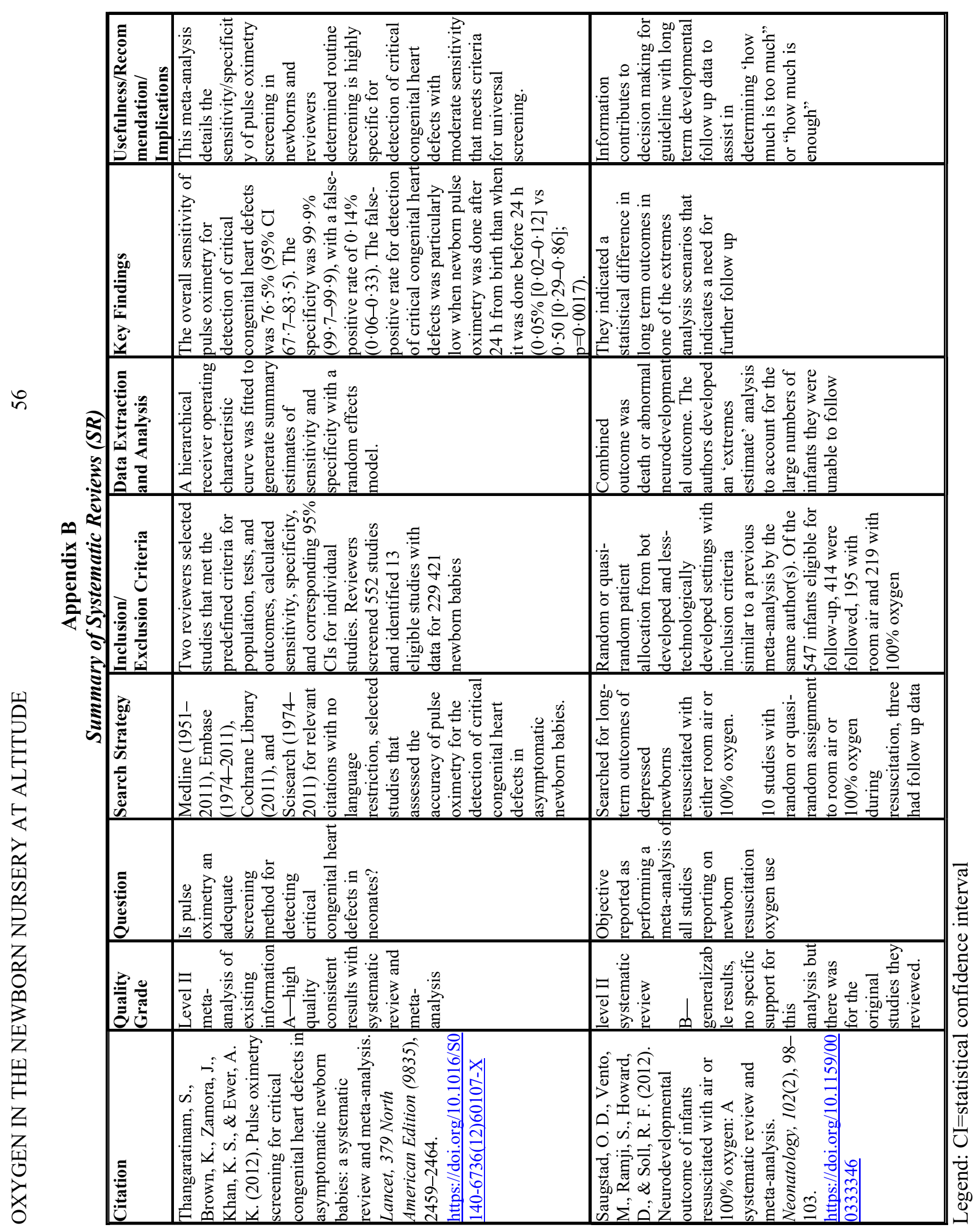




\section{Appendix C}

\section{Oxygen in the Newborn Nursery Clinical Practice Guideline}

\section{Introduction:}

The intent of this document is to provide consensus provider practice and nursing guidance for the delivery of care to newborns requiring oxygen, to include two additional care conditions unique to the neonate, the critical congenital heart disease (CCHD) screen and persistent pulmonary hypertension of the newborn (PPHN).

\section{Scope:}

This policy/resource applies to the Women and Infants Service Line in the normal newborn nurseries at both Central and North campuses.

\section{Guideline Details:}

\section{Definitions}

A. Neonatal Hypoxemia: Newborn with pre-ductal (right arm/hand/wrist) saturation $<\%$ in room air $\geq 30$ seconds without spontaneous recovery

B. Low Flow Nasal Cannula (LFNC): Oxygen administered from the wall at $100 \%$ with appropriately sized flowmeter and cannula for ordered flow

C. Critical Congenital Heart Disease Screening (CCHD): Evidence-based screening tool added to the newborn uniform screening panel at the recommendation of Health and Human Services (HHS) to improve early detection of critical congenital heart disease (CHD) in 2012 and implemented nationwide in 2018.

D. Persistent Pulmonary Hypertension of the Newborn (PPHN): Failure of the normal circulatory transition that occurs after birth characterized by elevated pulmonary pressures that causes hypoxemia secondary to right-to-left shunting of blood at the foramen ovale and ductus arteriosus, formerly known as persistent fetal circulation.

\section{Evaluate for Risk Factors}

A. Initial APGAR score $\leq 5$ or 5-minute APGAR lower than one-minute score

B. Need for positive pressure (CPAP or PPV) following delivery

C. Scheduled C-section (no labor)

D. Polyhydramnios

E. Meconium-stained amniotic fluid (MASF)

F. Failed CCHD

G. Echocardiographic findings consistent with PPHN

III. Lippincott Procedures (organizational hyperlinks)

A. Pulse oximetry, neonatal

B. Oxygen administration, nasal prongs, neonate

IV. Evaluation and treatment of infant with hypoxemia: (algorithm hyperlink)

A. Nursing assessment

1. Auscultation of lung fields noting

a. Quality and equality of breath sounds

b. Respiratory rate and depth

2. Assess for signs of respiratory distress including but not limited to:
a. Quality and equality of sounds
b. Respiratory rate and depth
c. Signs of respiratory distress 


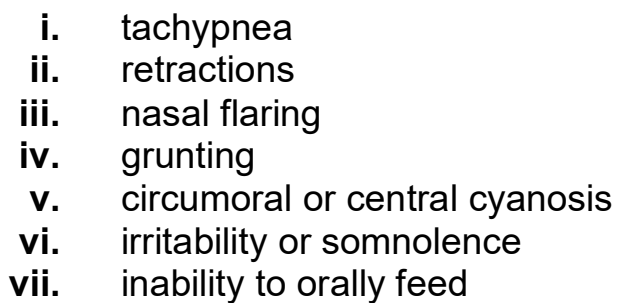

1. Oral feeding is not attempted in infants with respiratory rate $\geq$ 70

B. Oxygen initiation-follow algorithm

C. Monitoring

1. Continuous pulse oximetry and cardiopulmonary monitoring for at least one hour following delivery is indicated for infants at increased risk due to APGAR scoring or PPV

2. Place pulse oximeter probe on right hand/wrist (preductal saturation) if infant is $<24$ hours of age

a. May use any extremity if infant is $>24$ hours of age

b. Verify preductal saturation if reading is $<\%$

3. Infant to remain on continuous pulse oximetry and cardiopulmonary monitoring during any weaning attempts and during room air trial

D. Weaning-follow algorithm

E. Early Onset Sepsis (EOS) Calculator (for infants up to 24 hours of age)

1. If infant is on $>150 \mathrm{~mL}$ beyond four hours of age, return to EOS calculator recalculate equivocal exam

a. notify MD/NP if recommendations change from initial calculator recommendations

2. If an infant is placed on oxygen $\geq 60 \mathrm{~mL}$ at any time after four hours of age, return to EOS calculator, recalculate using both equivocal and clinical illness exam

F. Escalating care

a. notify MD/NP if recommendations change from initial calculator recommendations

1. Notify MD/NP if:

a. unable to begin weaning from $150 \mathrm{~mL}$ within one hour of oxygen initiation

b. infant displaying signs of respiratory distress (section IV.B.2.c)

2. Anticipate MD/NP reassessment or NICU evaluation and potential transfer

\section{Rooming-in on Oxygen-follow algorithm}

A. Discuss potential for infant to return to mother's room while on oxygen with MD/NP

B. Add pulse ox checks to surveillance vital signs (every 3-4 hours) until discharge

C. Educate parents to notify staff immediately for any signs of respiratory distress or cyanosis

VI. CCHD screen: (hyperlink to algorithm)

A. Performed $\geq 24$ hours of life

B. Place pulse oximeter preductal (right hand/wrist) and post-ductal (any other extremity. Ideally measurements are done simultaneously with infant in quiet state and supine position.

C. Any infant on LFNC beyond transition is returned to the nursery at approximately 22 hours of age for an attempt to wean to room air prior to screen.

D. Any infant unable to wean from LFNC at 24 hours of age the CCHD screen is indeterminate.

VII. Management of PPHN: increased oxygen flow to facilitate extrauterine transition

A. Once echocardiogram has been completed and presumptive diagnosis has been made, anticipate MD/NP order for LFNC up to $250 \mathrm{~mL}$ in collaboration with pediatric cardiology team

B. Weaning from oxygen is not attempted without specific provider order to do so

C. Infant may room in with mother until time of repeat $\mathrm{ECHO}$

D. If repeat echocardiogram is ordered, please call $\mathrm{ECHO}$ tech for an anticipated arrival time

1. Ideally, infant is returned to nursery 1-2 hours before repeat $\mathrm{ECHO}$ 
a. Attempt to place infant in room air, if infant has been on $250 \mathrm{~mL}$, may stop at 125 for 15-20 minutes before going to room air.

b. If infant unable to tolerate wean room air, ECHO is repeated on LFNC

2. If infant has desaturations on ordered flow or develops signs of distress (section IV.B.2.c), notify MD/NP immediately for NICU evaluation and potential transfer

VIII. Preparing for Discharge

A. If an infant, of any gestational age, is weaned to room air within four hours of discharge, a car seat test is performed with results documented and communicated to MD/NP before infant is sent home

B. Discuss potential need for home oxygen with MD/NP and insure order is placed if indicated

C. Notify respiratory therapy once order has been placed for set up and parent education-please remember to have room air saturation information readily available

\section{References:}

American Academy of Pediatrics. (2012). Levels of neonatal care. Pediatrics, 130(3), 587-597. https://doi.org/10.1542/peds.2012.1999

Császár-Nagy, N., \& Bókkon, I. (2018). Mother-newborn separation at birth in hospitals: A possible risk for neurodevelopmental disorders? Neuroscience and Biobehavioral Reviews, 84, 337-351.

https://doi.org/10.1016/j.neubiorev.2017.08.013

Grazel, R. (2018). Screening for CCHD with pulse oximetry: Where are we now? http://nann.org/publications/enews/november2018/special-interest-group

Hooper, S. B., Roberts, C., Dekker, J., \& te Pas, A. B. (2019). Issues in cardiopulmonary transition at birth. Seminars in Fetal and Neonatal Medicine, 24(6). https://doi.org/10.1016/j.siny.2019.101033

Lakshminrusimha, S., Konduri, G., \& Steinhorn, R. (2016). Considerations in the management of hypoxemic respiratory failure and persistent pulmonary hypertension in term and late preterm neonates. Journal of Perinatology, 36, S12-S19. https://doi.org/10.1038/jp.2016.44

Lakshminrusimha, S., \& Saugstad, O. (2016). The fetal circulation, pathophysiology of hypoxemic respiratory failure and pulmonary hypertension in neonates, and the role of oxygen therapy. Journal of Perinatology, 36, S3-S11. https://doi.org/10.1038/ip.2016.43

Olswang, L. B., \& Goldstein, H. (2017). Collaborating on the development and implementation of evidencebased practices: Advancing science and practice. Evidence-Based Communication Assessment Intervention, 11(3-4), 61-71. https://doi.org/10.1080/17489539.2017.1386404

Paranka, M. S., Brown, J. M., White, R. D., Park, M. V., Kelleher, A. S., \& Clark, R. H. (2018). The impact of altitude on screening for critical congenital heart disease. Journal of Perinatology, 38, 530-536.

https://doi.org/10.1038/s41372-018-0043-9

Note. Guideline formatting follows institution template 


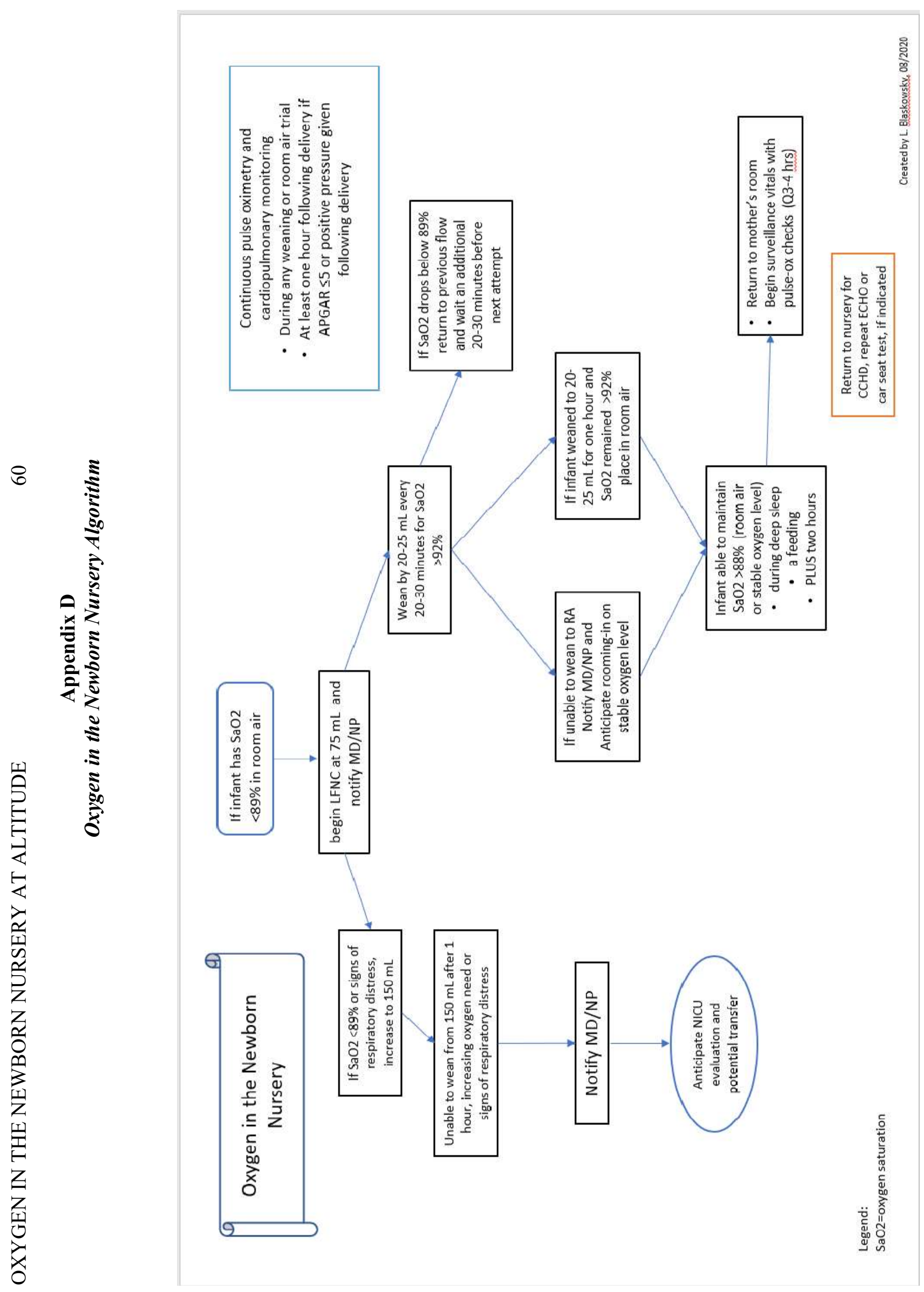


Appendix E

SWOT Analysis

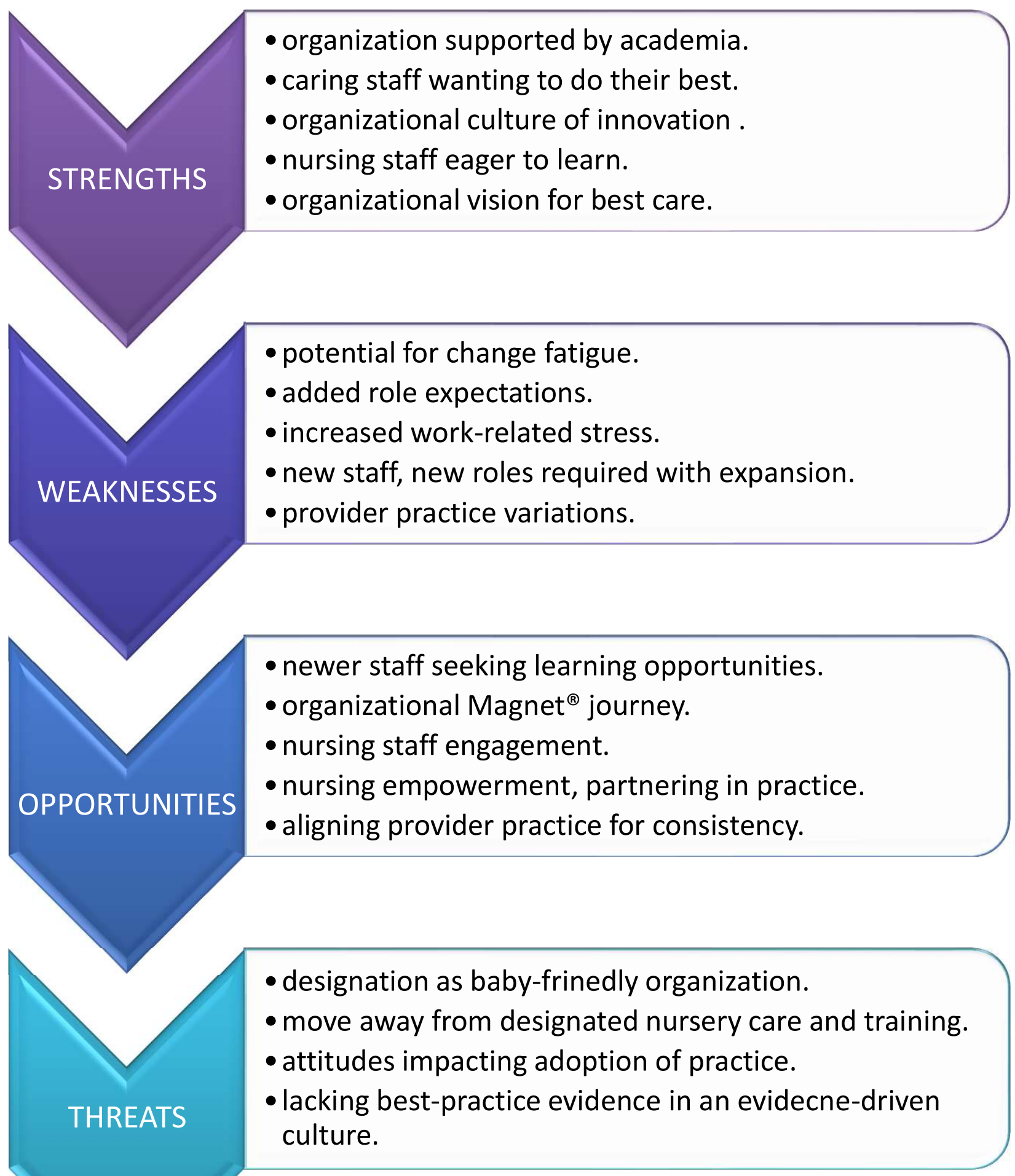




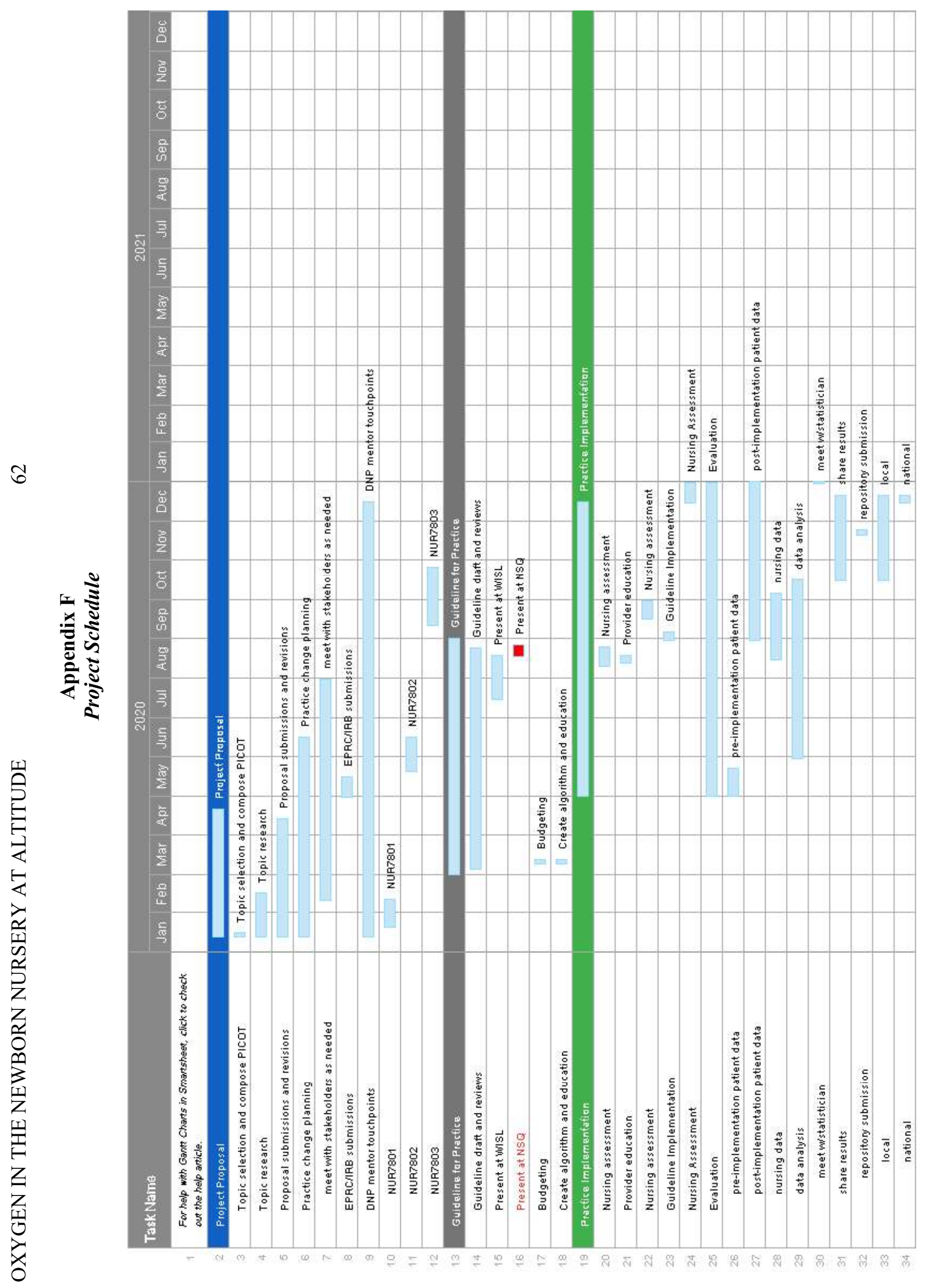




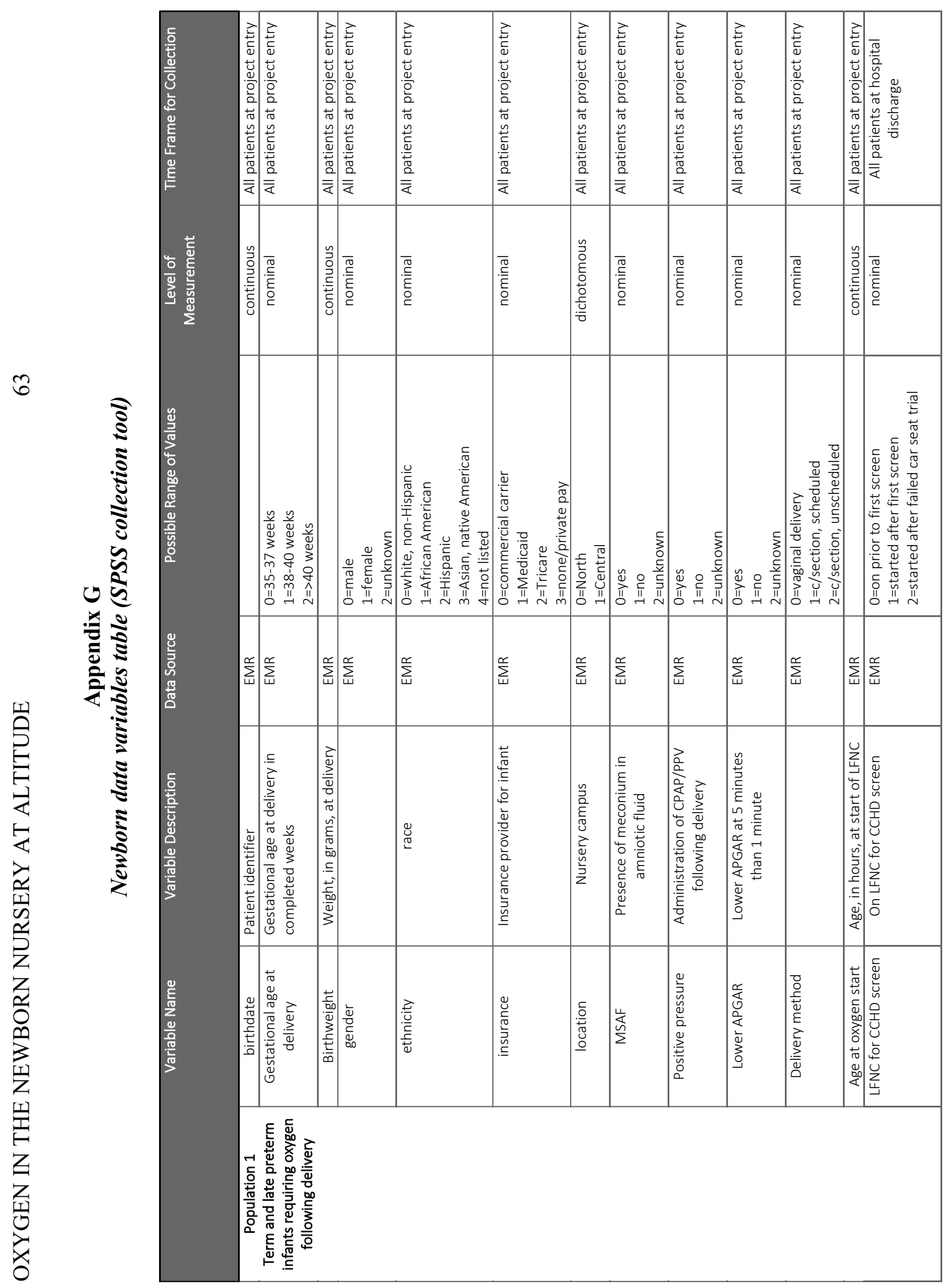




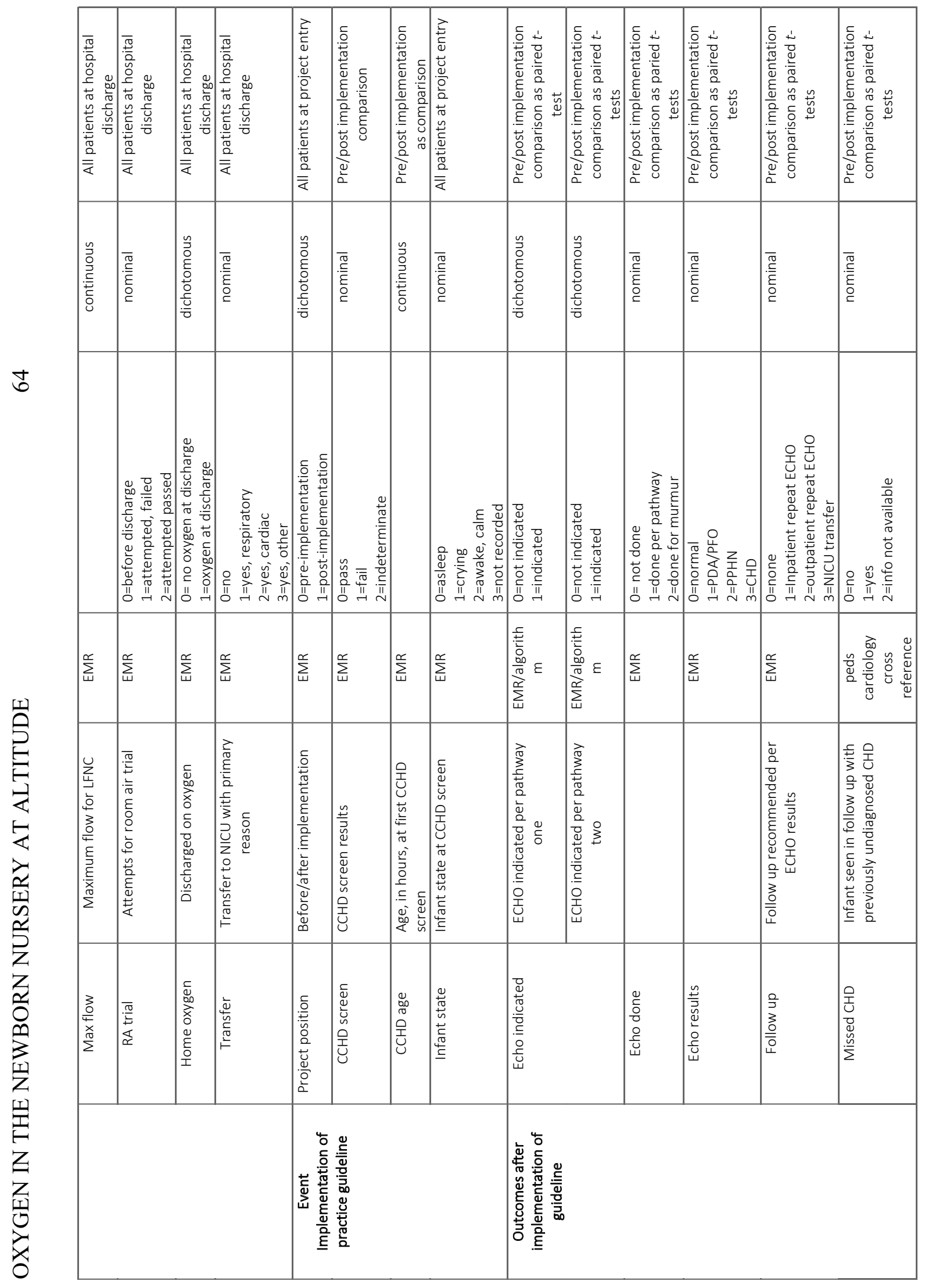




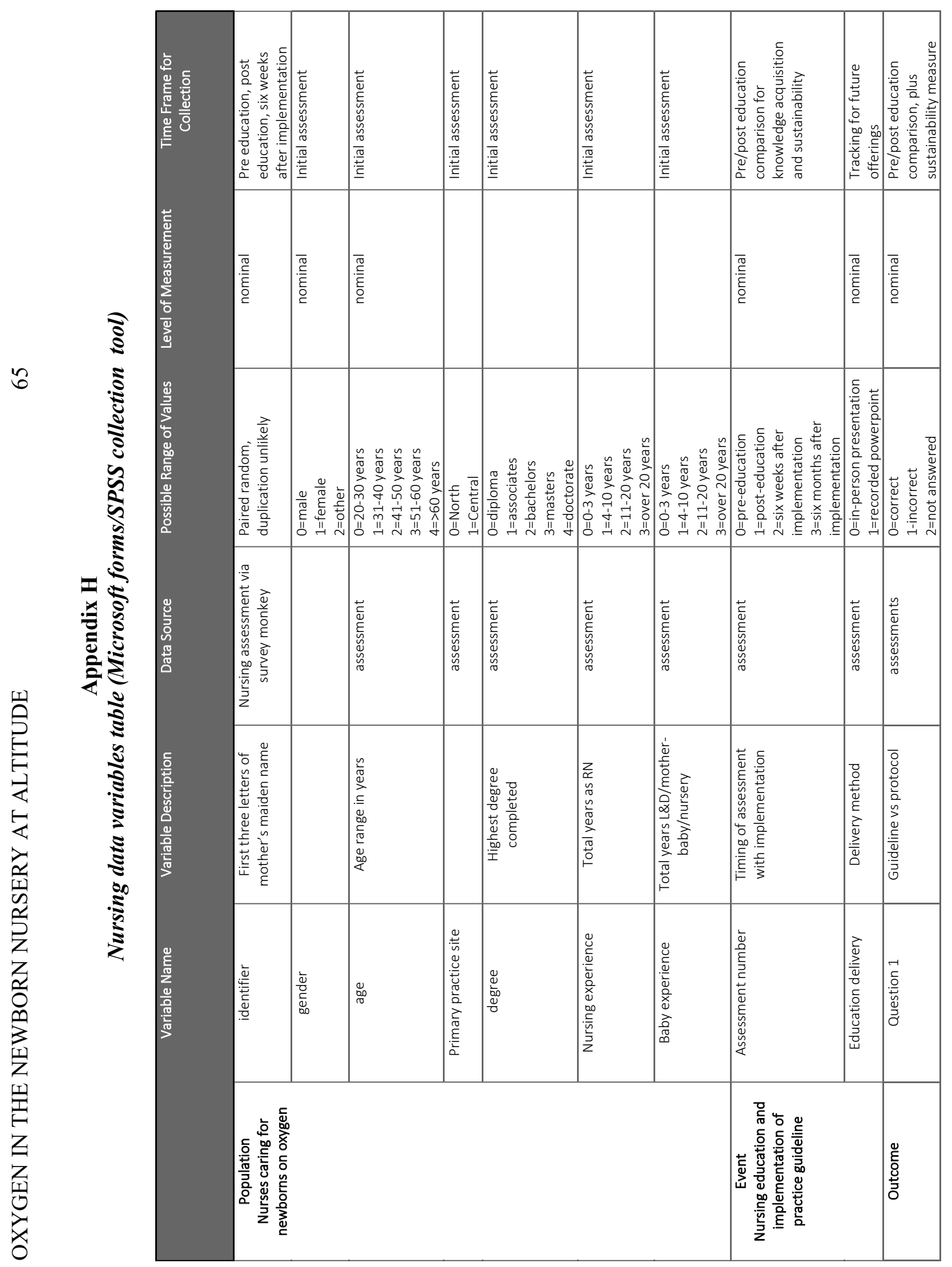




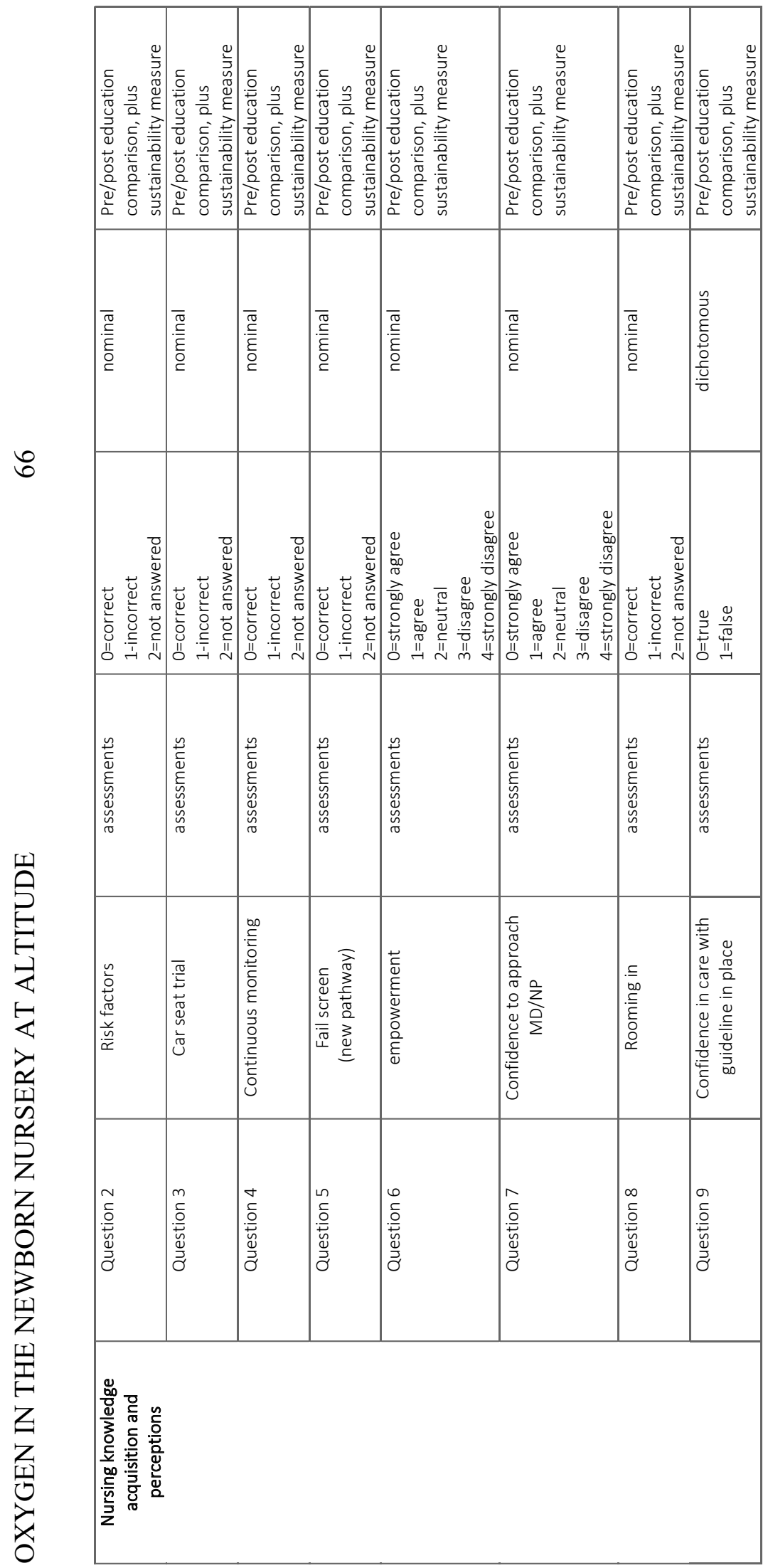




\section{Appendix I \\ Oxygen in the Newborn Nursery \\ Nursing Knowledge Test}

1. A guideline means all the steps must be followed, exactly, every single time.
a. True
b. False

2. Risk factors that may increase the risk for needing oxygen include:
a. Meconium-stained amniotic fluid
b. Scheduled C-section
c. Primigravida
d. Both $a$ and $b$
e. All of the above
f. None of the above

3. A car seat trial is indicated for an infant who was on oxygen and weaned to room air.
a. True
b. False

4. Continuous monitoring should continue:
a. For at least two hours
b. During a feeding
c. Include a deep sleep
d. Both a and c
e. All of the above
f. None of the above

5. An infant on oxygen at 24 hours fails CCHD screen an echocardiogram should be ordered.
a. True
b. False

6. I feel empowered, as a nurse, to discuss a patient plan of care with any provider
a. Strongly agree
b. Agree
c. Neutral
d. Disagree
e. Strongly disagree

7. I feel confident I can remind any provider about a guideline parameter
a. Strongly agree
b. Agree
c. Neutral
d. Disagree
e. Strongly disagree

8. An infant must remain in the nursery if unable to wean to room air for continuous monitoring
a. True
b. False

9. A guideline will give me more confidence in caring for an infant on oxygen
a. True
b. False 